\title{
Development of an electrotransformation protocol for genetic manipulation of Clostridium pasteurianum
}

\author{
Michael E Pyne ${ }^{1}$, Murray Moo-Young ${ }^{1}$, Duane A Chung ${ }^{1,2^{*}}$ and C Perry Chou ${ }^{1 *}$
}

\begin{abstract}
Background: Reducing the production cost of, and increasing revenues from, industrial biofuels will greatly facilitate their proliferation and co-integration with fossil fuels. The cost of feedstock is the largest cost in most fermentation bioprocesses and therefore represents an important target for cost reduction. Meanwhile, the biorefinery concept advocates revenue growth through complete utilization of by-products generated during biofuel production. Taken together, the production of biofuels from low-cost crude glycerol, available in oversupply as a by-product of bioethanol production, in the form of thin stillage, and biodiesel production, embodies a remarkable opportunity to advance affordable biofuel development. However, few bacterial species possess the natural capacity to convert glycerol as a sole source of carbon and energy into value-added bioproducts. Of particular interest is the anaerobe Clostridium pasteurianum, the only microorganism known to convert glycerol alone directly into butanol, which currently holds immense promise as a high-energy biofuel and bulk chemical. Unfortunately, genetic and metabolic engineering of C. pasteurianum has been fundamentally impeded due to lack of an efficient method for deoxyribonucleic acid (DNA) transfer.

Results: This work reports the development of an electrotransformation protocol permitting high-level DNA transfer to C. pasteurianum ATCC 6013 together with accompanying selection markers and vector components. The CpaAl restriction-modification system was found to be a major barrier to DNA delivery into C. pasteurianum which we overcame by in vivo methylation of the recognition site (5'-CGCG-3') using the M.FnuDII methyltransferase. With proper selection of the replication origin and antibiotic-resistance marker, we initially electroporated methylated DNA into C. pasteurianum at a low efficiency of $2.4 \times 10^{1}$ transformants $\mu \mathrm{g}^{-1}$ DNA by utilizing conditions common to other clostridial electroporations. Systematic investigation of various parameters involved in the cell growth, washing and pulse delivery, and outgrowth phases of the electrotransformation procedure significantly elevated the electrotransformation efficiency, up to $7.5 \times 10^{4}$ transformants $\mu \mathrm{g}^{-1} \mathrm{DNA}$, an increase of approximately three order of magnitude. Key factors affecting the electrotransformation efficiency include cell-wall-weakening using glycine, ethanol-mediated membrane solubilization, field strength of the electric pulse, and sucrose osmoprotection.

Conclusions: C. pasteurianum ATCC 6013 can be electrotransformed at a high efficiency using appropriately methylated plasmid DNA. The electrotransformation method and tools reported here should promote extensive genetic manipulation and metabolic engineering of this biotechnologically important bacterium.
\end{abstract}

Keywords: Biofuels, Butanol, Biobutanol, Clostridium pasteurianum, Electroporation, Genetic engineering, Glycerol, Methylation, Restriction, Transformation

\footnotetext{
* Correspondence: d28chung@uwaterloo.ca; cpchou@uwaterloo.ca

'Department of Chemical Engineering, University of Waterloo, 200 University

Avenue West, Waterloo, ON N2L 3G1, Canada

${ }^{2}$ Centurion Biofuels, Corp., Rm. 5113 Michael G. DeGroote Centre for

Learning and Discovery, 1280 Main Street West, Hamilton, ON L8S 4K1,

Canada
} 


\section{Background}

As a promising high-energy biofuel and bulk chemical, butanol is produced fermentatively by select members of the genus Clostridium [1]. Recent efforts to reinstate an economical fermentation-based butanol industry able to rival current petrochemical production routes have thus far proven uncompetitive [2]. Restrictive feedstock cost, accounting for up to $80 \%$ of total biobutanol production $[3,4]$, is often regarded as the chief factor limiting industrialization. Advantageously, tremendous expansion experienced by the global biodiesel industry in recent years has led to a significant oversupply of crude glycerol, which is generated as a waste stream representing approximately $10 \%(\mathrm{w} / \mathrm{w})$ of the unpurified biodiesel product [5-7]. In analogy to the biodiesel industry, immense rise in global bioethanol production has led to the accumulation of thin stillage, the aqueous fraction of whole stillage and an inexpensive waste product possessing a high proportion of unpurified, fermentable glycerol [8]. Accordingly, glycerol has become a highly attractive fermentable substrate due to its low cost and high degree of reduction.

Despite the notoriously wide substrate utilization range exhibited by the clostridia for butanol production, few species are able to grow on glycerol as a sole carbon and energy source. The prototypical industrial butanol producers, Clostridium acetobutylicum and C. beijerinckii, can only metabolize glycerol if the growth medium is supplemented with a less reduced carbon source, such as glucose [9], thus devaluing the economic advantages afforded by waste glycerol feedstocks. Though $C$. butyricum can ferment glycerol without glucose supplementation, it does not express a functional butanol biosynthetic pathway [10]. Among the clostridia, $C$. pasteurianum appears to be the only species that combines the capacity for glycerol dissimilation with a highly active butanol-producing pathway [11]. Under proper conditions for cultivation of C. pasteurianum using glycerol, butanol, ethanol, and 1,3-propanediol dominate, while organic acids are produced in only trace amounts [12]. Numerous recent studies have investigated the fermentation of pure and crude glycerol [10,12-17], in addition to thin stillage [18], by C. pasteurianum.

Unlike the past industrial workhorses, $C$. acetobutylicum and C. beijerinckii, C. pasteurianum has garnered nominal attention as a potential host for the production of butanol. This is largely due to the current inability to transfer DNA to C. pasteurianum, in addition to lack of a genome sequence for this organism. Based on early genetic studies, it appears efforts were in place to conduct genetic manipulation of $C$. pasteurianum, since a method for producing and regenerating protoplasts was developed [19] and a Type-II restriction endonuclease was identified as a potential barrier to gene transfer [20]. Successful conjugation-based plasmid transfer to $C$. pasteurianum has also been documented [20], yet no protocol has been described, nor have any genetic mutants arisen from this work. Accordingly, no genetic tools are currently available for the manipulation of C. pasteurianum. Recent efforts to improve C. pasteurianum butanol production have focused on traditional and less favorable random chemical mutagenesis techniques [21,22]. In order to construct superior C. pasteurianum strains through rational genetic and metabolic engineering strategies, it is pertinent to develop methods to transfer foreign DNA to this microorganism.

In contrast to Gram-negative bacteria, Gram-positive cells possess an extensive exterior network of peptidoglycan which physically restricts passage of exogenous DNA into the cell. For this reason, electrotransformation of Gram-positive species is generally less efficient than Gram-negative strains [23]. To overcome the thick Gram-positive cell wall, mild or brief pretreatment using cell-wall-weakening agents, such as lysozyme, glycine, DL-threonine, or penicillin $\mathrm{G}$, is commonly required to achieve optimal electrotransformation while maintaining sufficient cell viability $[23,24]$. Whereas some species of Clostridium can be electrotransformed without the use of cell-wall-weakening agents [25,26], others are electrotransformed at elevated levels when treated with such additives [27-29]. Poor electrotransformation efficiency of Gram-positive bacteria is further compounded within the clostridia due to the unusually high production of non-specific cell-wall-associated nucleases [26]. A number of highly-specific clostridial Type-II restriction endonucleases have also been identified $[25,26,30]$, including CpaAI from C. pasteurianum ATCC 6013 [20], highlighting the importance of DNA protection via methylation of the transforming DNA. Unidentified restriction-modification systems are likely the underlying cause of electrotransformation recalcitrance that has been observed with certain species, such as C. butyricum [31]. In summary, development of electrotransformation within the clostridia entails investigation of cell-wall-weakening additives, inactivation or evasion of non-specific nucleases, and protection of foreign DNA against highly specific restriction endonucleases, in addition to examination of other common parameters involved in the cell growth, washing and pulse delivery, and recovery phases of the standard bacterial electrotransformation procedure [23,24].

As an entry point to allow genetic manipulation of $C$. pasteurianum, here we report the development of an electroporation-mediated transformation system for $C$. pasteurianum ATCC 6013. CPaAI was validated as a major restriction endonuclease attacking foreign DNA delivered into $C$. pasteurianum and this mechanistic limitation was resolved by in vivo methylation of the recognition site (5'-CGCG-3') prior to electroporation. Methylation alone, however, did not result in high-level 
transfer of DNA into C. pasteurianum. Instead, through systematic investigation, we developed an efficient electrotransformation method that is dependent on weakening of the cell wall using glycine, ethanol-mediated membrane solubilization, a low electric field, and osmotic stabilization afforded by sucrose. In addition to the electroporation protocol, we also identified effective antibiotic selection systems and origins of replication capable of sustaining plasmids in C. pasteurianum. To our knowledge, this study presents the first demonstration of DNA transfer into C. pasteurianum with a high efficiency and opens an avenue for extensive genetic and metabolic engineering of C. pasteurianum.

\section{Results}

\section{Protection of plasmid DNA from CpaAl restriction}

To develop a C. pasteurianum transformation protocol, we first assayed crude cell lysates for the presence of restriction-modification systems, which potently inhibit plasmid DNA transfer to bacteria. At least one Type-II restriction endonuclease, designated CpaAI with 5'CGCG-3' recognition and an isoschizomer of ThaI and FnuDII, has been previously identified in cell-free lysates of C. pasteurianum ATCC 6013 [20]. We initially prepared crude cell lysates through sonication of whole cells. As found in other species, such as $C$. acetobutylicum $[26,32]$, lysates generated in this manner potently degraded all plasmid DNA substrates, presumably due to non-specific cell-wall-associated nucleases (data not shown). To overcome non-specific nuclease activity, we then aimed to assay CpaAI restriction activity using protoplast extracts, which allowed clear detection of CpaAI activity. Optimal digestion occurred between 24 hours incubation at $37^{\circ} \mathrm{C}$ and produced a restriction pattern identical to that of BstUI, a commercial isoschizomer of CpaAI (Figure 1A). Since all known BstUI isoschizomers catalogued in REBASE [33] are sensitive to methylation of both external cytosine residues within the 5'-CGCG-3' recognition sequence, we next assessed the effect of external cytosine methylation by expression of the M.FnuDII methyltransferase (with

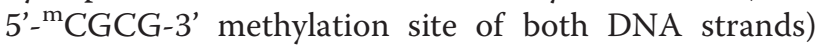
from plasmid pFnuDIIMKn. M.FnuDII methylation protected pMTL85141, an E. coli-Clostridium shuttle vector [34], from degradation by CpaAI and BstUI (Figure 1B). While unmethylated substrates were significantly restricted after 2 hours incubation at $37^{\circ} \mathrm{C}$, M.FnuDII-methylated substrates were completely resistant to cleavage, even after $8 \mathrm{~h}$. Note that methylated pMTL85141 plasmid preparations, which also contains the pFnuDIIMKn methylating plasmid, migrated at a different molecular weight than unmethylated plasmid preparations. However, when we linearized the doubleplasmid preparation, in addition to preparations of the two individual plasmids, we observed no detectable changes in plasmid size or unexpected products (Figure 1B, right panel). In vitro methylation with commercial M.SssI (5'- ${ }^{\mathrm{m}}$ CG-3' methylation site) and M.CviPI (5'-GmC-3' methylation site) methyltransferases also protected plasmids from digestion by $\mathrm{CpaAI}$ in protoplast extracts and commercial BstUI (not shown).

\section{Initial electrotransformation of $C$. pasteurianum}

To electrotransform C. pasteurianum, we employed a series of E. coli-Clostridium shuttle vectors which differ only in their Gram-positive origins of replication: pMTL82151 (pBP1 ori from C. botulinum); pMTL83151 (pCB102 ori from C. butyricum); pMTL84151 (pCD6 ori from C. difficile); and pMTL85141 (pIM13 ori from Bacillus subtilis) [34]. We utilized conditions common to clostridial electrotransformation procedures (Table 1) and M.FnuDII-methylated DNA. Of the four vectors tested, pMTL83151, pMTL84151, and pMTL85141 yielded colonies using thiamphenicol selection, corresponding to electrotransformation efficiencies of $0.7 \times 10^{1}, 0.3 \times 10^{1}$, and $2.4 \times 10^{1}$ transformants $\mu \mathrm{g}^{-1} \mathrm{DNA}$, respectively. Accordingly, pMTL85141 was selected as the vector used for all subsequent electrotransformation work. Importantly, no transformants were obtained with unmethylated plasmid, validating the necessity to protect transforming DNA against the endogenous CpaAI restriction endonuclease. Interestingly, while in vivo methylation was essential for transformation, we did not obtain transformants when pMTL85141 was methylated in vitro with M.SssI or M. CviPI methyltransferases, although both enzymes protect pMTL85141 from digestion by CpaAI. This result is unexpected, but is speculated upon later in this report.

To confirm the presence of pMTL85141 in transformed colonies, we screened thiamphenicol-resistant colonies for the presence of the catP resistance marker within pMTL85141 using colony PCR (Figure 2A). All of the colonies screened generated a single expected product of $518 \mathrm{bp}$. To further confirm the presence of plasmid and determine if rearrangements or recombinations occurred upon transfer to C. pasteurianum, plasmid pMTL85141was isolated and purified from thiamphenicol-resistant colonies and digested with XhoI. XhoI digestion of all plasmid preparations from $C$. pasteurianum yielded a single band on a $1.0 \%$ agarose gel, similar to the digestion of pMTL85141 prepared from E. coli DH5 $\alpha$ (Figure 2B). The presence of the methyltransferase vector, pFnuDIIMKn, could not be detected in C. pasteurianum plasmid preparations.

\section{High-level electrotransformation of C. pasteurianum}

An electrotransformation efficiency of $2.4 \times 10^{1}$ transformants $\mu^{-1}$ DNA is very low relative to the efficiency of other clostridia (i.e., up to $10^{6}$ transformants $\mu \mathrm{g}^{-1}$ DNA [35]) and did not permit transfer of certain 


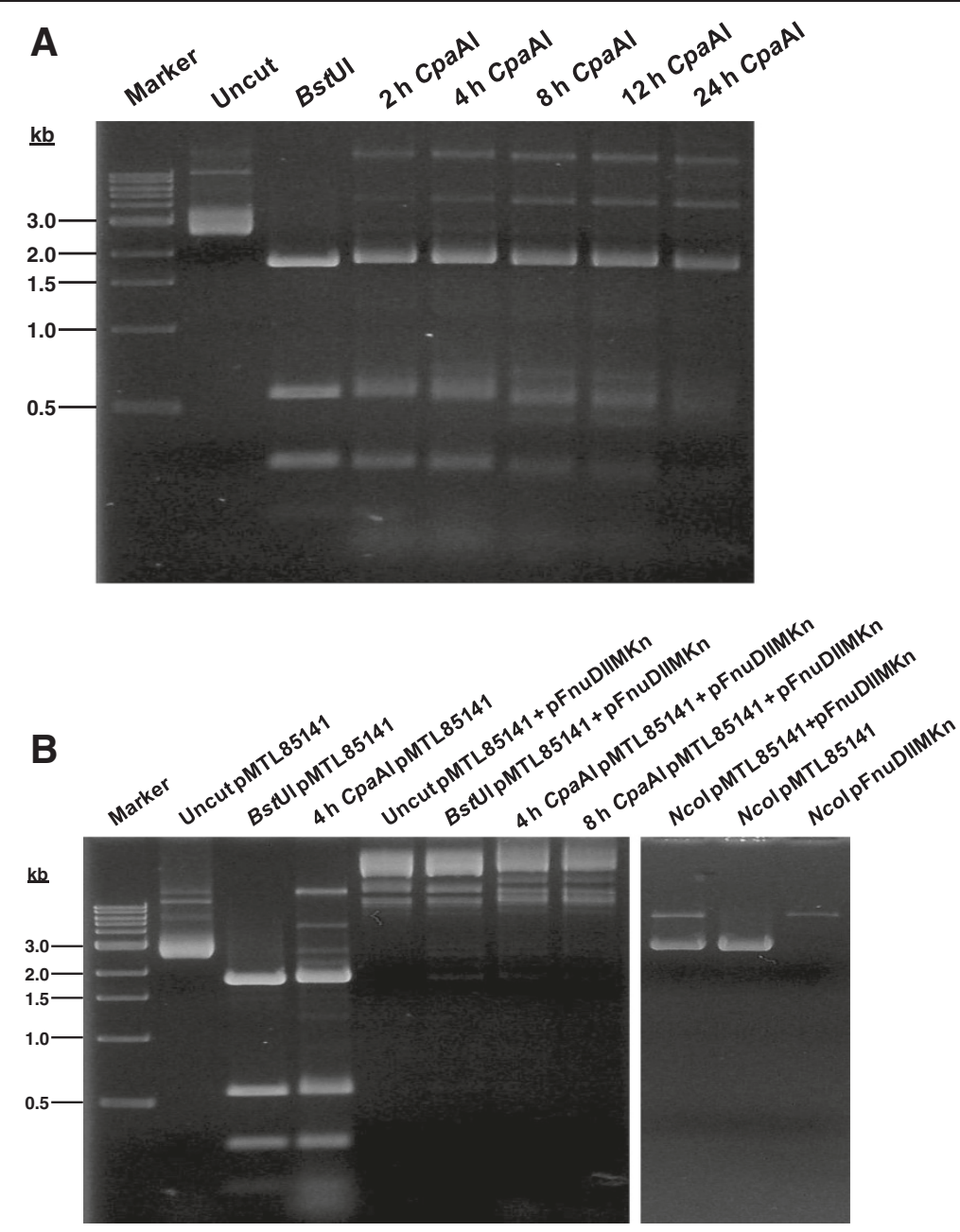

Figure 1 M.FnuDII methyltransferase-mediated protection of pMTL85141 against CpaAl endonuclease. A. Time course digestion of pMTL85141 using crude protoplast extracts possessing CpaAl restriction activity, resolved on a $2 \%$ agarose gel. Digestion reactions contained $1.0 \mathrm{\mu g}$ pMTL85141 and 25\% protoplast extract in a total volume of $20 \mu \mathrm{l} 1 \times$ CpaAl custom buffer. For comparison, pMTL85141 is shown undigested and digested with BstUI, a commercial isoschizomer of CpaAl. Expected digestion products are 1785, 581, 270, 252, and 75 bp. B. M. FnuDII-mediated protection of pMTL85141 from CpaAl digestion (left panel). Protoplast extract digestions contained $1.0 \mu \mathrm{g}$ pMTL85141 or pMTL85141+pFnuDIIMKn, the vector harboring the M.FnuDII methyltransferase gene, and 25\% protoplast extract in a total volume of $20 \mu \mathrm{l} 1 \times$ CpaAl custom buffer. pMTL85141 preparation in the presence of plasmid pFnuDIIMKn afforded protection of pMTL85141 from both BstUI and CpaAl restriction, as no digestion products could be detected. Methylation treatment resulted in the presence of high-molecular weight bands. Linearization of the high molecular weight bands by Ncol digestion (right panel) confirmed the presence of pMTL85141 (2,963 bp) and the methylating plasmid, pFnuDIIMKn (6,449 bp), at the correct sizes of the individual linearized vectors.

gene knockout vectors, as described later in this report. Therefore, we were prompted to develop a high-level electrotransformation protocol by systematically investigating the effects on electrotransformation efficiency of parameters throughout all phases of the electrotransformation procedure. Electrotransformation efficiencies reported below represent the average of at least two electrotransformation experiments using the same preparation of electrocompetent cells.

(i) Cell-wall-weakening. We first investigated the use of cell-wall-weakening agents due to their potential to greatly enhance electrotransformation by weakening of the Gram-positive cell wall [24]. A screening experiment was conducted to identify potential additives capable of enhancing electrotransformation of C. pasteurianum, including glycine, DL-threonine, lysozyme, and penicillin G (Figure 3A). Individually, we screened the effect of glycine and DL-threonine by supplying the additives in the presence of $0.25 \mathrm{M}$ sucrose at the first signs of growth $\left(\mathrm{OD}_{600}\right.$ of 0.3-0.4) because cultures failed to grow to sufficient cell densities if glycine or DL-threonine were present without sucrose supplementation or if the additives 
Table 1 Consensus clostridial electrotransformation conditions leading to initial low-level transformation of $C$. pasteurianum

\begin{tabular}{|c|c|c|c|}
\hline Electrotransformation parameter & Consensus for Clostridium species & Low-level transformation of $C$. pasteurianum & Selected references \\
\hline \multicolumn{4}{|l|}{ Cell growth } \\
\hline Growth medium & YTG or $2 \times Y T G$ & $2 \times Y T G$ & {$[44,58,59]$} \\
\hline $\begin{array}{l}\text { Growth phase and } \mathrm{OD}_{600} \text { at time } \\
\text { of harvest }\end{array}$ & mid to late exponential phase $\left(\mathrm{OD}_{600} 0.5-0.9\right)$ & $\mathrm{OD}_{600} 0.6-0.8$ & [25] \\
\hline \multicolumn{4}{|l|}{ Washing and pulse delivery } \\
\hline Wash and electroporation buffer & $\begin{array}{l}\text { 5-7 } \mathrm{mM} \text { sodium phosphate, } \mathrm{pH} \text { 6.5-7.4, containing } 270 \mathrm{mM} \text { sucrose } \\
\text { and } 1 \mathrm{mM} \mathrm{MgCl} 2\end{array}$ & $\begin{array}{l}5 \mathrm{mM} \text { sodium phosphate, } \mathrm{pH} 6.5 \text {, containing } 270 \mathrm{mM} \text { sucrose } \\
\text { and } 1 \mathrm{mM} \mathrm{MgCl}\end{array}$ & {$[25,26,29]$} \\
\hline Number of wash steps & 1 & 1 & {$[44,45,58]$} \\
\hline Cuvette gap width & $0.4 \mathrm{~cm}$ & $0.4 \mathrm{~cm}$ & {$[29,45,46]$} \\
\hline Volume of cells & $600 \mu \mathrm{l}$ & $600 \mu \mathrm{l}$ & [26] \\
\hline Pulse parameters & 2.0-2.5 kV; $25 \mu \mathrm{F} ; 200-800 \Omega ; 4-8 \mathrm{~ms}$ & $2.0-2.5 \mathrm{kV} ; 25 \mu \mathrm{F} ; 200-800 \Omega ; 6-9 \mathrm{~ms}$ & {$[44,46]$} \\
\hline \multicolumn{4}{|l|}{ Outgrowth } \\
\hline Recovery and plating medium & YTG or $2 \times Y T G$ & $2 \times Y T G$ & {$[58,59]$} \\
\hline Transformation efficiency & Up to $10^{6}$ transformants $\mu g^{-1}$ DNA & $2.4 \times 10^{1}$ transformants $\mu \mathrm{g}^{-1}$ pMTL85141 & [35] \\
\hline
\end{tabular}



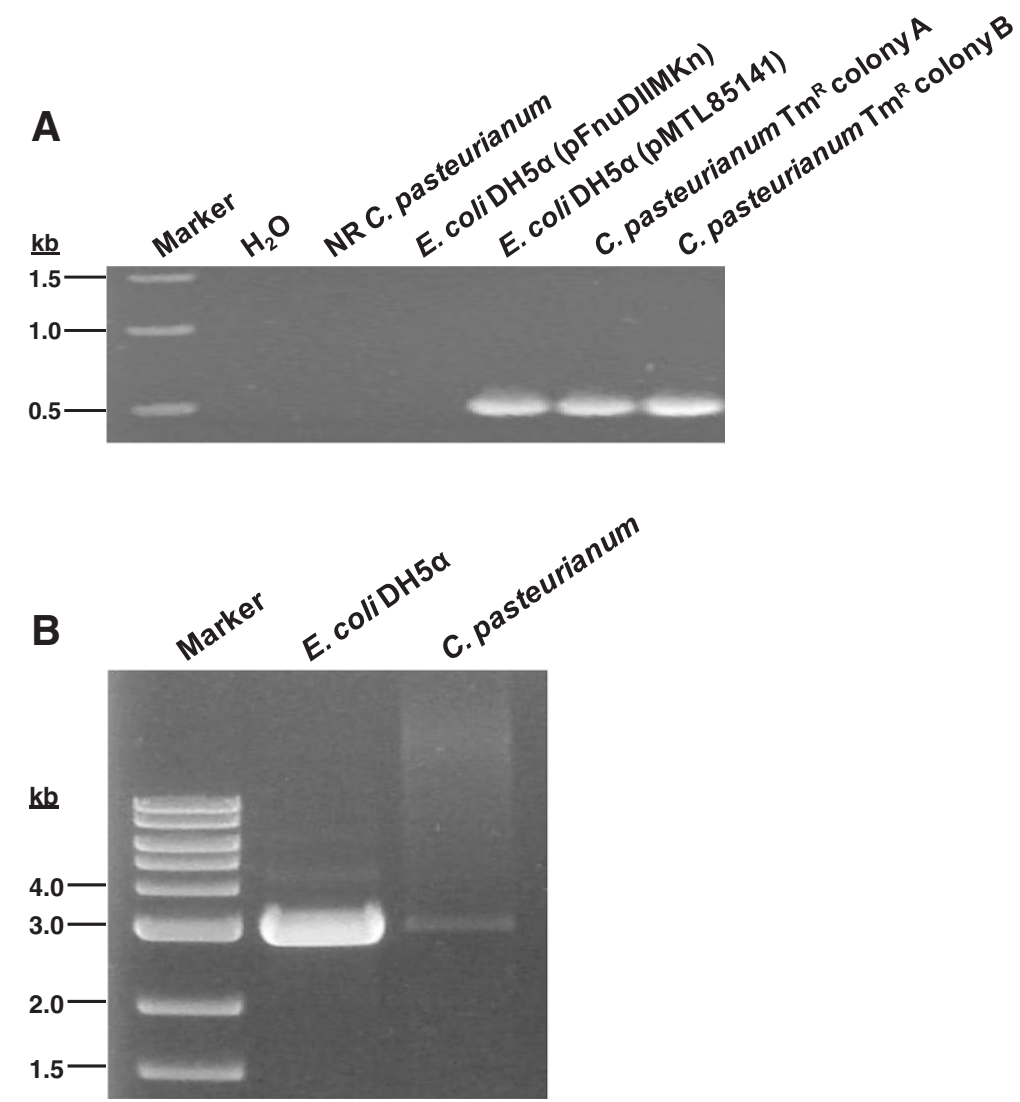

Figure 2 Low-level electrotransformation of $\boldsymbol{C}$. pasteurianum. A. Colony PCR confirmation of pMTL85141 presence in C. pasteurianum transformants using primers pMTL.seq.S and pMTL.seq.AS. The expected product of 518 bp could only be amplified from E. coli transformed with pMTL85141 and from thiamphenicol-resistant C. pasteurianum colonies, and not from non-recombinant [66] C. pasteurianum. B. Xhol-linearized pMTL85141 plasmid prepared from E. coli DH5a and from a representative transformant of C. pasteurianum showing the expected plasmid size of $2,963 \mathrm{bp}$. Some undigested vector remains visible in the E. coli preparation.

were present at the time of inoculation. Cell growth rate was slightly reduced in the presence of both glycine and DL-threonine. On the other hand, lysozyme and penicillin $\mathrm{G}$ were screened by addition at the wash stage in the wash and electroporation buffer, followed by incubation at $37^{\circ} \mathrm{C}$ for 30 minutes prior to electroporation. Additive concentrations were chosen based on previous electrotransformation studies with various species of Gram-positive bacteria [29,36-39]. Of the four additives screened, only glycine and DL-threonine improved the electrotransformation efficiency. The samples treated with $40 \mu \mathrm{g} / \mathrm{ml}$ lysozyme and $30 \mu \mathrm{g} /$ $\mathrm{ml}$ penicillin $\mathrm{G}$ even failed to grow during the outgrowth period following electroporation, potentially due to cell lysis. Despite a slight inhibition on cell growth, more than 7-fold enhancement of electrotransformation efficiency was attained using $1.5 \%$ glycine, compared to the control experiment with no cell-wall-weakening agent. Supplementation of 20 and $40 \mathrm{mM}$
DL-threonine provided approximately 1.6- and 2.1fold increases, respectively, in electrotransformation efficiency. Although glycine and DL-threonine have different mechanisms of cell wall disruption, combining glycine and DL-threonine treatments did not lead to a synergistic increase in electrotransformation efficiency. As a result of the clear benefit of glycine on the electrotransformation efficiency, we set out to determine the optimum glycine regimen with respect to concentration and duration of exposure. This investigation was done concomitant with investigating the effect of sucrose on electrotransformation efficiency by providing osmoprotection during the various cell-wallweakening glycine treatments. We tested glycine at $0.75,1.0$, and $1.25 \%$ in the presence of either 0.25 or $0.4 \mathrm{M}$ sucrose, corresponding to nearly isotonic and hypertonic extracellular environments, respectively. The highest glycine concentration was selected as $1.25 \%$ to minimize growth inhibition, 


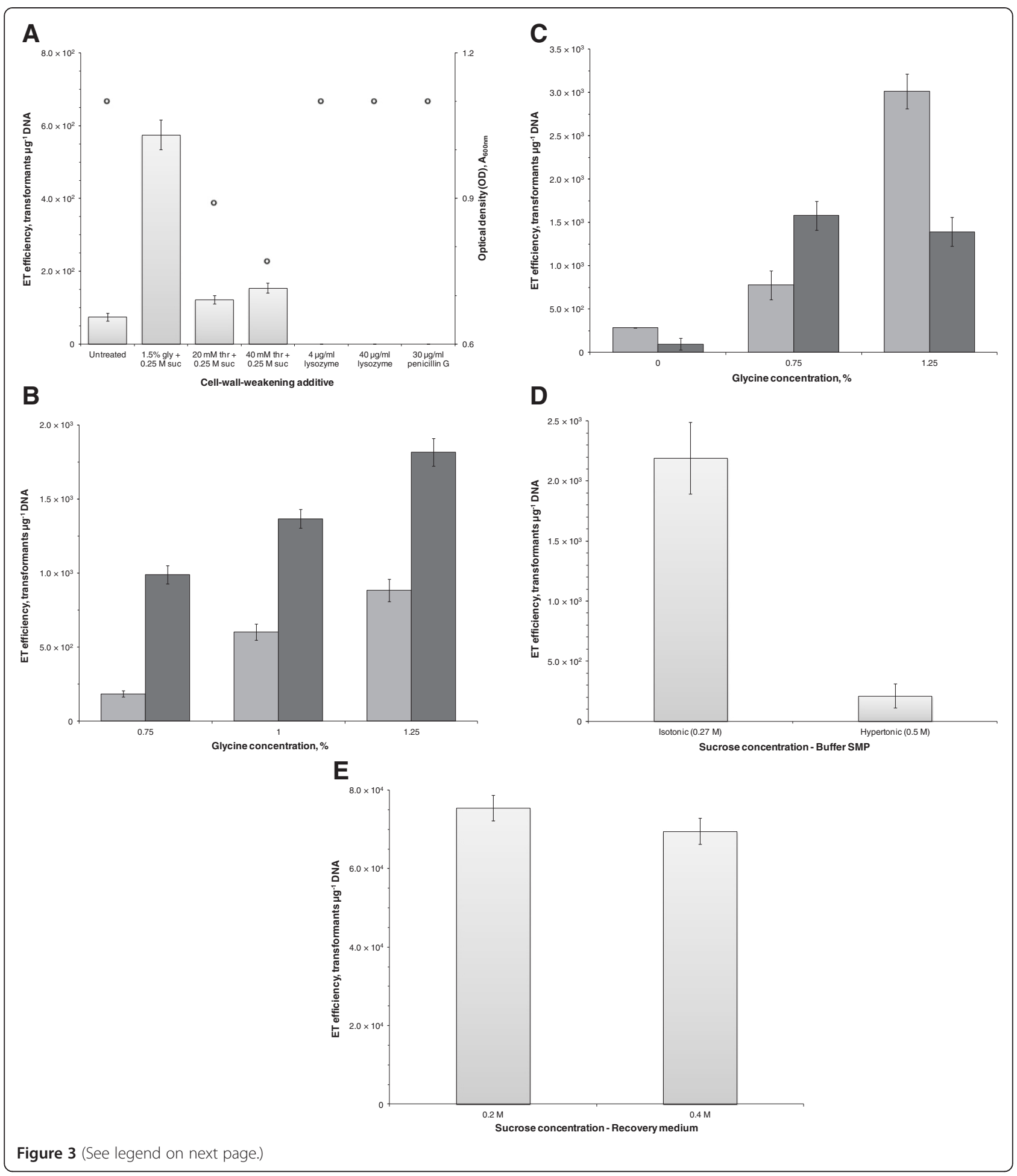


(See figure on previous page.)

Figure 3 Investigation of cell-wall-weakening and osmoprotection on electrotransformation of C. pasteurianum. A. Investigation of cellwall-weakening agents. Cells were grown to early exponential phase $\left(\mathrm{OD}_{600} 0.3-0.4\right)$ and glycine (gly) or DL-threonine (thr) was added along with $0.25 \mathrm{M}$ sucrose (suc). For lysozyme and penicillin $\mathrm{G}$ treatments, additives were supplemented to buffer SMP prior to electroporation and incubated anaerobically at $37^{\circ} \mathrm{C}$ for 30 minutes. An untreated culture was included as a control. The $\mathrm{OD}_{600}$ of each culture at time of harvest is shown (o). Pulse duration was unaffected between samples. B. Investigation of glycine and sucrose concentrations. Six cultures were grown to an $\mathrm{OD}_{600}$ of 0.4 and glycine was added to a final concentration of $0.75,1.0$, or $1.25 \%$ together with sucrose at 0.25 (light shading) or $0.4 \mathrm{M}$ (dark shading). Growth was minimally affected between samples, as all cultures attained a final $\mathrm{OD}_{600}$ of 1.2-1.5. Pulse duration was unaffected between samples. C. Investigation of glycine concentration and duration of exposure. Two cultures were grown to an $\mathrm{OD}_{600} \mathrm{Of}_{0.4}$ and glycine was added to a final concentration of 0.75 or $1.25 \%$ together with $0.4 \mathrm{M}$ sucrose. An additional control culture was prepared without either glycine or sucrose supplementation. Cells were harvested, washed, and electroporated at either 2.5 (light shading) or 4 hours (dark shading) following supplementation with glycine and sucrose. Pulse duration was unaffected between samples. D. Effect of sucrose concentration within the wash and electroporation buffer. Cultures were washed and electroporated in SMP buffer containing either isotonic $(0.27 \mathrm{M})$ or hypertonic sucrose $(0.5 \mathrm{M})$. Pulse duration was unaffected between samples. E. Effect of sucrose concentration within the outgrowth medium. Cultures were electroporated and resuspended and grown in 2XYTG medium containing either 0.2 or $0.4 \mathrm{M}$ sucrose.

which becomes significant at concentrations equal to or greater than $1.5 \%$. Increasing the sucrose concentration from 0.25 to $0.4 \mathrm{M}$ led to a significant increase in electrotransformation efficiency under all glycine concentrations tested (Figure 3B). To examine the effect of the duration of glycine exposure on electrotransformation efficiency, cultures were incubated with $0,0.75$, or $1.25 \%$ glycine in the presence of $0.4 \mathrm{M}$ sucrose starting at an $\mathrm{OD}_{600}$ of 0.4 for either 2.5 or 4.5 hours prior to washing and pulse delivery (Figure 3C). Maximum electrotransformation efficiency was attained by exposing cells to $1.25 \%$ glycine for 2.5 hours in the presence of $0.4 \mathrm{M}$ sucrose, a 10.7-fold increase compared to the untreated control culture. Interestingly, lower glycine concentrations could be compensated for by increasing the duration of exposure. When using a glycine concentration of $0.75 \%$ in the growth medium, 4.5 hours rather than 2.5 hours of exposure generated a greater electrotransformation efficiency at this lower glycine concentration, although the absolute gain in electrotransformation efficiency was still lower than with $1.25 \%$ glycine.

(ii) Osmoprotection. We continued to investigate the effect of the osmoprotectant concentration on electrotransformation efficiency during the subsequent washing and electroporation phase and the outgrowth phase following electroporation. Cells grown in the presence of $1.25 \%$ glycine and $0.4 \mathrm{M}$ sucrose were washed and electroporated in the common clostridial SMP buffer containing either $0.27 \mathrm{M}$ (isotonic) or $0.5 \mathrm{M}$ (hypertonic) sucrose (Figure 3D). SMP buffer outperformed other buffers tested, such as 10\% PEG 8000, 15\% glycerol, protoplast buffer with lysozyme omitted, and SMP buffer supplemented with $15 \%$ glycerol (data not shown). Hypertonic sucrose, which improved the electrotransformation efficiency when included during the growth phase, reduced electrotransformation efficiency by a factor of 10.3 when included at the washing and electroporation phase. Thus, 0.27 M sucrose was adopted as the optimum sucrose concentration in the wash and electroporation buffer.

To assess the effect of sucrose osmoprotection during cell recovery immediately following delivery of the electric pulse, cells were grown, made electrocompetent, pulsed, and resuspended in $10 \mathrm{ml} 2 \times$ YTG containing either 0.2 or $0.4 \mathrm{M}$ sucrose (Figure 3E). Similar to the washing and electroporation phase, hypertonic sucrose again reduced electrotransformation efficiency, although the effect was modest (a 1.1-fold decrease), and thus, $0.2 \mathrm{M}$ was adopted as the optimum sucrose concentration in the outgrowth medium.

(iii) Cell membrane solubilization. After developing a regimen to weaken the exterior cell wall while supporting cell viability with sucrose osmoprotection, we next sought to enhance transfer of plasmid DNA to C. pasteurianum with the use of ethanol to solubilize the cell membrane, a strategy which has proved effective with some species of Gram-negative bacteria $[40,41]$. We also extended this approach to butanol, which elicits a more pronounced toxic effect on cells. To achieve maximum membrane solubilization without adversely affecting cell viability, we utilized concentrations near the toxicity threshold for many species of Clostridium, which were up to $15 \%$ (v/v) for ethanol and $2 \%(\mathrm{v} / \mathrm{v})$ for butanol $[42,43]$. Five minutes prior to electroporation, ethanol or butanol was added directly to the cell-DNA suspension. Ethanol added at 5 and $10 \%$ provided a 1.6- and 1.3-fold respective increase in electrotransformation efficiency, compared to the control experiment with no ethanol treatment (Figure 4). Butanol, and ethanol at an elevated concentration of $15 \%$, proved 


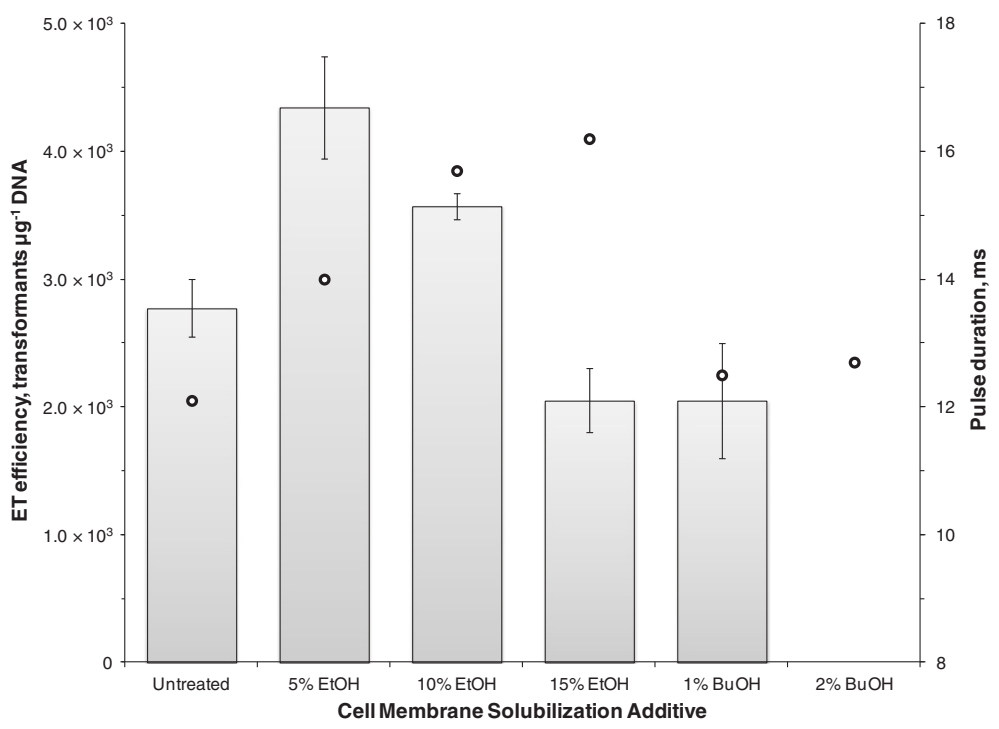

Figure 4 Investigation of membrane permeabilization on the electrotransformation of $\boldsymbol{C}$. pasteurianum. Immediately prior to pulse delivery, cell-DNA suspensions were supplemented with 5, 10, or 15\% ethanol (EtOH) or 1 or $2 \%$ butanol (BuOH). An untreated sample was included as a control. The time constant of each pulse is shown (o). The sample treated with $2 \%$ butanol failed to grow during the allotted 16 -hour recovery period following electroporation.

to be detrimental to electrotransformation. The $2 \%$ butanol sample grew extremely slowly during the outgrowth period following electroporation. The addition of ethanol increased the pulse time constant, which may have influenced electrotransformation efficiency (Figure 4). Butanol did not significantly affect the pulse time constant.

(iv) Electric pulse parameters. We investigated the effects of the electrical pulse with respect to voltage (i.e., field strength), capacitance, and resistance (Figure 5A-C). In an initial screening experiment, low voltages in the range of $1.8-2.0 \mathrm{kV}$ generated significantly more transformants than voltages of 2.0-2.5 kV (data not shown), which are representative of most electrotransformation protocols using species of Clostridium [29,44-46]. Hence, pulses of 1.6, 1.8, and $2.0 \mathrm{kV}$ were administered, corresponding to field strengths of 4.0, 4.5, and $5.0 \mathrm{kV} \mathrm{cm}^{-1}$ (Figure 5A), using a capacitance of $25 \mu \mathrm{F}$ and a resistance of $\infty \Omega$ (i.e., without the use of Pulse Controller module). A voltage of $1.8 \mathrm{kV}$ was found to produce the greatest electrotransformation efficiency, although pulses of 1.6 and $2.0 \mathrm{kV}$ only slightly reduced the electrotransformation efficiency. Pulse duration decreased by approximately $1 \mathrm{~ms}$ when increasing pulse voltage from 1.6 to $1.8 \mathrm{kV}$ and from 1.8 to $2.0 \mathrm{kV}$. Next, capacitances of 25 and $50 \mu \mathrm{F}$ were assessed at voltages of 1.8 and $2.25 \mathrm{kV}$, and $\infty \Omega$ (Figure 5B). At both voltages, increasing the capacitance from 25 to $50 \mu \mathrm{F}$ reduced electrotransformation efficiency by a factor of 2.7 $(1.8 \mathrm{kV})$ and $15.6(2.25 \mathrm{kV})$, respectively. Similarly, decreasing resistance from $\infty \Omega$ to 200 and $600 \Omega$, at $2.25 \mathrm{kV}$ and $25 \mu \mathrm{F}$ was unproductive and resulted in a 3.3- and 2.3-fold decrease in electrotransformation efficiency, respectively (Figure 5C). Pulse duration changes were not predictive of the effects on electrotransformation efficiency, as increases in the time constant accompanying changes in capacitance and decreases in the time constant accompanying changes in resistance both correlated with decreased electrotransformation efficiency.

(v) DNA quantity and outgrowth duration. Finally, we evaluated the effect of DNA amount on both number of transformants and electrotransformation efficiency (Figure 6A) and the effect of the duration of outgrowth following electroporation. Although the total number of transformants was found to increase linearly between 0.5 and $5.0 \mu \mathrm{g}$ of pMTL85141, the greatest electrotransformation efficiency occurred using $0.5 \mu \mathrm{g}$ of plasmid DNA. Transformants could be detected at the lowest quantity of DNA tested, $0.25 \mu \mathrm{g}$, and saturation with pMTL85141 was not observed up to $5.0 \mu \mathrm{g}$, the highest quantity of DNA tested.

For assessing outgrowth duration, we incubated electroporated cells for $0,2,4,6$, or 16 hours prior to plating on selective medium. Growth in the form of gas formation and increased culture turbidity could be detected 

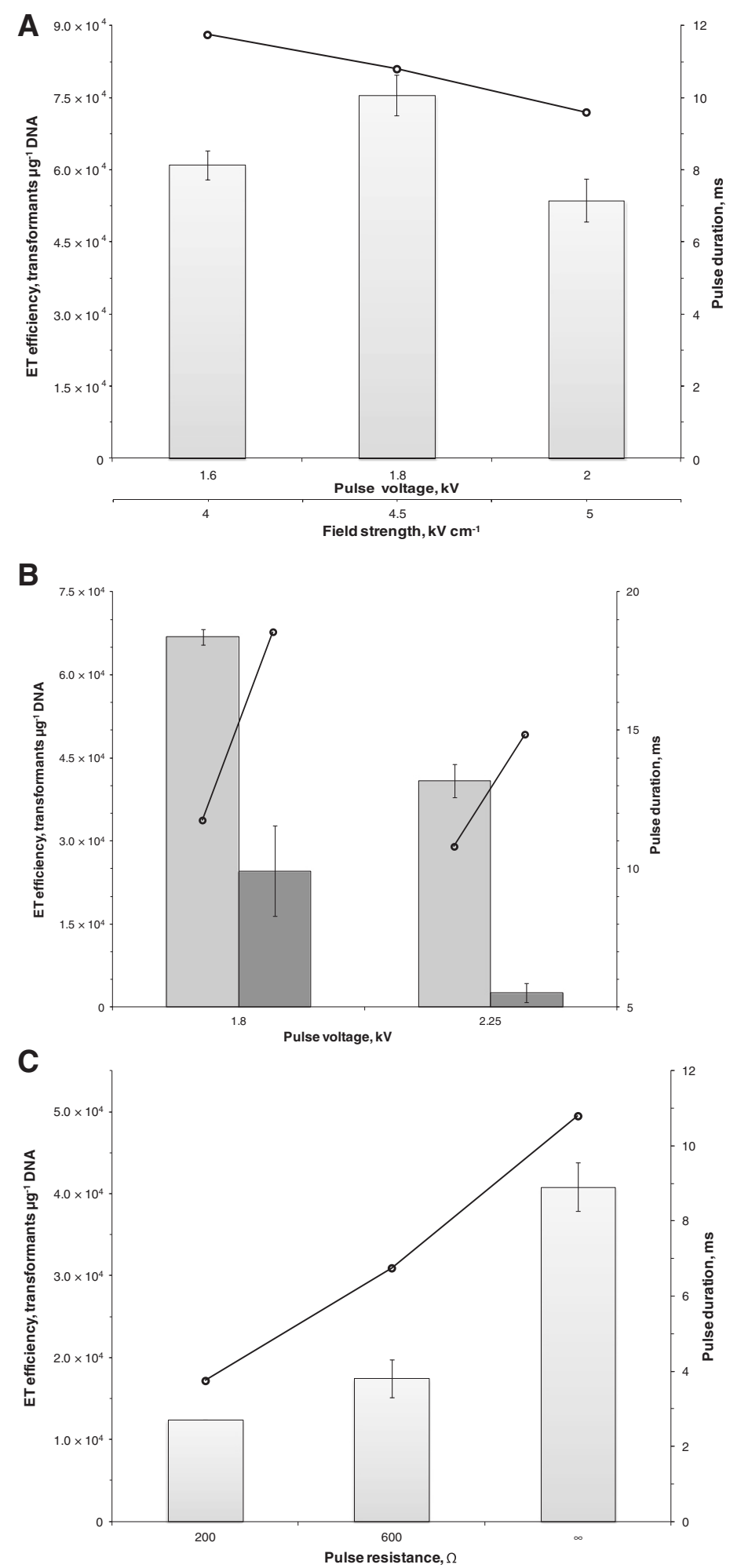

Figure $\mathbf{5}$ Investigation of electric pulse parameters on the electrotransformation of $\boldsymbol{C}$. pasteurianum. A. Effect of pulse voltage (field strength). Electrotransformation efficiency was measured using electric pulses of 1.6, 1.8, or $2.0 \mathrm{kV}$, corresponding to field strengths of 4.0, 4.5, and $5.0 \mathrm{kV} \mathrm{cm}^{-1}$. The time constant of each pulse is shown (o). B. Effect of pulse capacitance. Electrotransformation efficiency was measured at 25 (light shading) and $50 \mu \mathrm{F}$ (dark shading) under voltages of 1.8 and $2.25 \mathrm{kV}$. The time constant of each pulse is shown (o). C. Effect of pulse resistance. Electrotransformation efficiency was measured at 200,600, and $\infty \Omega$ at a voltage of $2.25 \mathrm{kV}$. The time constant of each pulse is shown (o). 

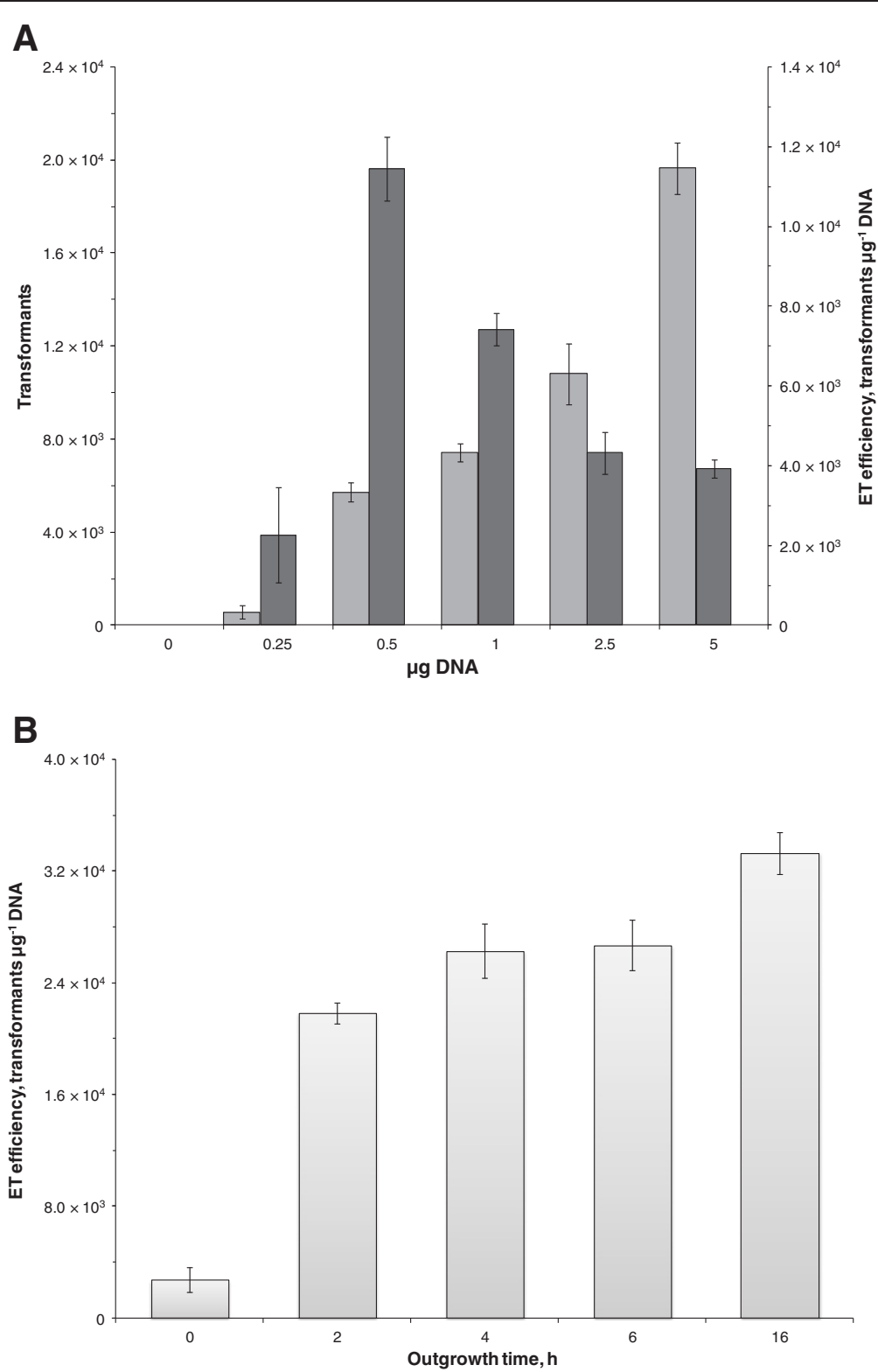

Figure 6 Investigation of amount of DNA and outgrowth duration on the electrotransformation of $C$. pasteurianum. A. Effect of plasmid DNA amount on total number of transformants and electrotransformation efficiency of $C$. pasteurianum. Separately, $0,0.25,0.5,1.0,2.5$, and $5.0 \mu \mathrm{g}$ of pMTL85141 were added to electrocompetent cells of C. pasteurianum and electroporated. Total number of thiamphenicol-resistant transformants (light shading) and electrotransformation efficiency (dark shading) were quantified. Pulse duration was unaffected between samples. Zero $\mu \mathrm{g}$ pMTL85141 failed to generate thiamphenicol-resistant transformants. B. Effect of post-electroporation incubation time. Cells were electroporated, transferred to $10 \mathrm{ml}$ outgrowth medium containing $0.2 \mathrm{M}$ sucrose, and incubated for $0,2,4,6$, or 16 hours prior to selective plating.

as early as 2 hours following transfer to recovery medium. Transformants could be obtained without recovery (i.e., 0 hours incubation), although at a significantly reduced efficiency (7.9- to 12.1 -fold reduction compared to 2-16 hours incubation) (Figure 6B). As expected, the greatest electrotransformation efficiency was attained using the longest recovery time tested (i.e., 16 hours), which was approximately 1.3 -fold greater than at 4-6 hours outgrowth, during which time the electrotransformation efficiency was unchanged. While 16 hours of outgrowth is a convenient duration due to the length of the pre-growth and washing and electroporation phases, electrotransformation efficiency for clostridia is typically reported following 4-6 hours of outgrowth. Thus, the electrotransformation efficiencies reported here, all of which involved 16 hour outgrowth experiments, can be divided by 1.3 for comparision to other clostridial electroporation efficiencies. 


\section{Application of the electrotransformation protocol to other vectors}

Since many clostridial vectors favor the $\operatorname{erm} B$ determinant for erythromycin or clarithromycin selection, rather than catP-based thiamphenicol selection used in this study, we constructed pMTL85141ermB, a dual catP and ermB selectable plasmid. Comparable, high-level electrotransformation efficiencies (1.0-1.4 $\times 10^{4}$ transformants $\left.\mu \mathrm{g}^{-1} \mathrm{DNA}\right)$ were obtained by selection of pMTL85141ermB using $15 \mu \mathrm{g} / \mathrm{ml}$ thiamphenicol, $4 \mu \mathrm{g} / \mathrm{ml}$ clarithromycin, or $20 \mu \mathrm{g} / \mathrm{ml}$ erythromycin. Control plasmid transformations lacking the erm $B$ determinant failed to generate clarithromycin- or erythromycin-resistant colonies. Therefore, ermB-based clarithromycin or erythromycin selection is effective using C. pasteurianum.

To determine the generality of our high-efficiency electrotransformation protocol for other vectors, we also attempted electrotransfer of pSY6catP into C. pasteurianum. pSY6catP is a modified form of pSY6 [47] whereby the ermB erythromycin-resistance determinant is replaced with catP from pMTL85141. pSY6 is one of several E. coli-Clostridium shuttle vectors (in addition to, e.g., the ClosTron system of vectors [48]), which harbours the Ll.trB group II intron machinery necessary for performing intron-mediated gene knockouts in clostridia. A pSY6-based vector was chosen because it possesses the same pIM13 replicon as pMTL85141, thereby eliminating potential variation in efficiency due to differences in the origin of replication. Unexpectedly, pSY6catP transformed C. pasteurianum at a significantly decreased efficiency of $1.1 \times 10^{1}$ transformants $\mu^{-1}$ DNA, an efficiency approximately 1,000-fold lower than achieved with pMTL85141. To rule out a vector size effect on the reduction in electrotransformation efficiency (pSY6catP is 8,498 bp, whereas pMTL85141 is 2,963 bp), we also attempted to transform pHT3, a 7,377 bp vector with the same fundamental vector components as pMTL85141ermB, in addition to a heterologous lacZ gene from Thermoanaerobacterium thermosulfurogenes EM1 [49] (Table 2). Unlike pSY6catP, pHT3 transformed at a high efficiency of $1.8 \times 10^{4}$ transformants $\mu \mathrm{g}^{-1} \mathrm{DNA}$, which is comparable to pMTL85141ermB. Therefore, the dramatic reduction in electrotransformation efficiency is likely not due to differences in plasmid size. At this point, we hypothesize the presence of an additional unidentified restriction system which targets certain common site(s) of pSY6catP, but not pMTL85141, pMTL85141ermB, or pHT3, much like the $d c m$-methylation-dependent restriction systems recently addressed in C. thermocellum and $C$. ljungdahlii $[27,50]$. Our observation of the transformability of in-vivo-methylated plasmids, but not in-vitro-methylated plasmids, may also be the result of an unidentified methylation-dependent restriction system, which may or may not be the same one affecting PSY6catP. The in vitro M.SssI and M.CviPI methyltransferases we utilized, with
5'- ${ }^{\mathrm{m}} \mathrm{CG}-3$ ' and 5'-G ${ }^{\mathrm{m}} \mathrm{C}-3$ ' methylation sites, respectively, each methylate a larger number of sites than the M.FnuDII in vivo methyltransferase (5'- ${ }^{\mathrm{m}} \mathrm{CGCG}-3$ ' methylation site). Since certain DNA substrates containing 5-methylcytosine are restricted, it is likely that over-methylated pMTL85141 could be unexpectedly targeted by a Type II or Type IV 5methylcytosine-specific restriction endonuclease in $C$. pasteurianum. Experiments are underway to probe for an additional restriction system in C. pasteurianum. Nonetheless, even with the reduced electrotransformation efficiency of pSY6catP, we have used it to successfully introduce type II introns into the C. pasteurianum genome in preliminary experiments (data not shown), whereas this was not possible with the low-level electrotransformation efficiency we initially obtained prior to our electrotransformation studies detailed in this report.

\section{Discussion}

Lack of a gene transfer system has fundamentally hindered genetic manipulation of C. pasteurianum. We report here the first development of an electroporation-mediated procedure for high-level gene transfer to C. pasteurianum. The first step in overcoming this barrier involved confirming the previously identified C. pasteurianum restriction endonuclease, CpaAI, which cleaves 5'-CGCG-3' nucleotide sequences. In vivo methylation using the $\mathrm{M}$. FnuDII methyltransferase allowed protection of E. coli-C. pasteurianum shuttle vectors. Active protoplast extracts of C. pasteurianum completely degraded pMTL85141 prepared from $E$. coli $\mathrm{DH} 5 \alpha$, but not when prepared from $E$. coli ER1821 harboring both pMTL85141 and pFnuDIIMKn (Figure 1A, B). This finding allowed us to demonstrate low-level electrotransformation of $C$. pasteurianum by using conditions commonly utilized for clostridial electroporation (Table 1). Despite repeated attempts, unmethylated pMTL85141 (i.e., prepared from $E$. coli $\mathrm{DH} 5 \alpha$ in the absence of plasmid pFnuDIIMKn) was unable to transform $C$. pasteurianum, confirming the requirement for proper methylation of plasmid DNA prior to electrotransformation. Plasmid transfer was confirmed through colony-PCR-amplification, isolation and purification, and DNA sequencing of plasmid pMTL85141 from thiamphenicol-resistant colonies (Figure 2A, B; data not shown). The resulting plasmid preparation from $C$. pasteurianum was devoid of rearrangements and recombination and could only transform restrictiondeficient strains of E. coli, such as ER1821. The initial efficiency of approximately $2.4 \times 10^{1}$ transformants $\mu^{-1}$ DNA paled in comparison to electrotransformation levels achieved with other species of Clostridium (up to $10^{6}$ transformants $\mu^{-1}$ DNA [35]) and prevented transfer of low-level-transforming vectors, such as pSY6catP (discussed below). Thus, we investigated the effects of several parameters critical for the electrotransformation 
Table 2 Strains, plasmids, and oligonucleotides

Strain Relevant characteristics

Source or reference

Escherichia coli DH5a

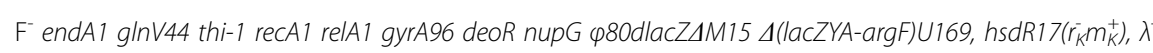

Lab stock

Escherichia coli ER182

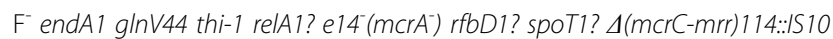

Clostridium pasteurianum Wild-type

ATCC 6013

\section{Plasmid}

pET-20b(+)

pETKnFRT

pFnuDIIM

pFnuDIIMKn

PHT3

PIMP1

pKD4

PMTL82151

pMTL83151

pMTL84151

pMTL85141

pMTL85141ermB

pSC12

pSY6

pSY6catP

\section{Oligonucleotide}

KnFRT.BIpl.S

KnFRT.Xhol.AS

ermB.Ndel.S

ermB.Pvul.AS

catP.BCIl.S

PSC12.SOE.AS

pSC12.SOE.S

catP.Clal.AS

pMTL.seq.S

\section{Relevant characteristics}

E. coli pET-series expression vector (Ap ${ }^{\mathrm{R}}$; ColE1 ori)

Lab stock; New England Biolabs

American Type Culture

Collection

Derived by inserting the FRT-flanked kan gene of pKD4 into the MCS of pET-20b(+) (Ap ${ }^{R}$; ColE1 ori; FRT-Kn ${ }^{R}$-FRT)

Source or reference

The M.FnuDII methyltransferase gene of Fusobacterium nucleatum inserted into the tet gene of pACYC184 (p15A ori; $\mathrm{Cm}^{\mathrm{R}}$ )

Novagen

This study

[65]

This study

E. coli-C. pasteurianum shuttle vector containing lacZ from Thermoanaerobacterium thermosulfurogenes EM1 (Ap ${ }^{R}$; ColE1 ori; Erm ${ }^{R}$; pIM13 ori) [49]

E. coli-C. pasteurianum shuttle vector (Ap ${ }^{\mathrm{R}}$; ColE1 ori; Erm ${ }^{\mathrm{R}}$; pIM13 ori)

Template vector (Ap ${ }^{R}$; pR6K ori; FRT-Kn ${ }^{R}$-FRT)

$[70]$

E. coli-C. pasteurianum shuttle vector $\left(\mathrm{Cm}^{\mathrm{R}}\right.$; ColE1 ori; $\mathrm{PBP} 1$ ori)

E. coli-C. pasteurianum shuttle vector ( $\mathrm{Cm}^{\mathrm{R}}$; ColE1 ori; pCB102 ori)

E. coli-C. pasteurianum shuttle vector $\left(\mathrm{Cm}^{\mathrm{R}}\right.$; ColE1 ori; $\mathrm{pCD} 6$ ori)

[34]

[34]

[34]

E. coli-C. pasteurianum shuttle vector ( $\mathrm{Cm}^{\mathrm{R}}$; ColE1 ori; plM13 ori)

[34]

Derived by insertion of the ermB gene of pIMP1 into PMTL85141

This study

E. coli-C. pasteurianum shuttle vector ( $\mathrm{Cm}^{\mathrm{R}}$; ColE1 ori; plM13 ori)

E. coli-C. pasteurianum expression vector carrying the L. lactis ItrB group II intron under control of the C. acetobutylicum ptb promoter, and ItrA ORF (Ap ${ }^{R}$; ColE1 ori; ErmR ; pIM13 ori)

Derived by replacing the ermB gene of pSY 6 with the catP gene from pSC12

[47]

Sequence $\left(5^{\prime}-3^{\prime}\right)^{*}$

ACACGTGCTCAGCGATTGTGTAGGCTGGAGCTGCTTCG

GCCATGCTCGAGATGAATATCCTCCTTAGTTCCTATTCC

ATTACGCATATGTITGGCTAACACACACGCCATTCC

CTITTCGATCGTTTCCGACGCTTATTCGCTTCGCT

GTITGATCATGGTCTITGTACTAACCTGTGG

tacagcatgaccgttaaagtgg

ccactttaacggtcatgctgtaAGTGCAAGGTACACTTGCAAAGTAGTGG

GGATCGATCCAACTTAATCGCCTTGCAGCACA

GGGAGGTCAATCTATGAAATGCG

pMTL.seq.AS

CGGAGCATTTGGCTTTCCTTCCAT

* Lower case: overlap sequences used in SOE PCR; Underline: restriction recognition sequences. 
of Gram-positive bacteria. With the modified protocol, we were able to elevate the electrotransformation efficiency to a maximum of $7.5 \times 10^{4}$ transformants $\mu \mathrm{g}^{-1} \mathrm{DNA}$, an increase of more than three orders of magnitude from the original low-level electrotransformation efficiency (Table 3). The electroporation parameters determined to be most influential on the electrotransformation of C. pasteurianum are discussed in detail below.

Gram-positive bacteria are electrotransformed at efficiencies several orders of magnitude lower than Gramnegative cells, highlighting the importance of effective weakening of the Gram-positive cell wall prior to electroporation. The most widely used additives for this purpose are glycine, DL-threonine, lysozyme, and penicillin $\mathrm{G}$, all of which were screened in this study (Figure 3A). Under the conditions tested, only glycine and DL-threonine afforded enhanced levels of electrotransformation, with glycine rendering the cell most susceptible to electrotransformation. Glycine has been widely used for increasing electrotransformation efficiency of Grampositive bacteria [36,37,39,51-56] and its mode of action has been extensively studied [57]. Specifically, glycine is incorporated into the peptidoglycan network through replacement of critical D- and L-alanine residues, generating a weakened cell wall due to a lesser degree of cross-linking [57]. To balance glycine supplementation with cell viability, we determined that optimum electroporation is achieved using brief exposure to the highest glycine concentration that still permits sufficient cell growth. The optimized glycine regimen for $C$. pasteurianum involves exposure of early exponential phase cells to $1.25 \%$ glycine for 2-3 hours (Figure 3B, C), which is most similar to protocols developed for Mycobacterium avium [37],
Bacillus subtilis [54], and B. thuringiensis [55]. Of particular importance is the timing of glycine addition. Specifically, glycine should be added only when the cells enter the exponential growth phase, as glycine supplementation at the time of inoculation resulted in significant growth inhibition. While cell-wall-weakening is not an indispensable requirement for electrotransformation of C. pasteurianum, a significant increase in electrotransformation efficiency was obtained with glycine treatment. To our knowledge this study represents the first use of glycine as a cell-wall-weakening and electroporation-enhancing agent within the Clostridium genus.

Upon treatment with glycine, cells possess a compromised cell wall, and therefore, it is paramount that cells be stabilized osmotically. Our results clearly demonstrate the importance of sucrose osmoprotection during glycine treatment, as cultures without sucrose supplementation failed to grow in the presence of glycine. Although $0.25 \mathrm{M}$ sucrose in the growth medium was sufficient to promote growth, increasing the concentration to $0.4 \mathrm{M}$ afforded a significant enhancement to electrotransformation (Figure 3B). In opposition to the growth medium, however, hypertonic sucrose in the recovery medium $(0.4 \mathrm{M})$ was found to have a slightly negative effect on electrotransformation efficiency compared to a slightly hypotonic environment $(0.2 \mathrm{M})$ (Figure 3E). A greater degree of osmotic stabilization is likely required in the growth medium compared to the recovery medium as a result of cell-wall-weakening that occurs in the presence of glycine. In a similar manner, hypertonic sucrose $(0.5 \mathrm{M})$ in the wash and electroporation buffer greatly reduced electrotransformation efficiency compared to an isotonic buffer $(0.27 \mathrm{M})$

Table 3 Summary of protocol for high-level electrotransformation of C. pasteurianum and comparison to initial lowlevel protocol

\begin{tabular}{|c|c|c|}
\hline Electrotransformation parameter & Low-level protocol & High-level protocol \\
\hline \multicolumn{3}{|l|}{ Cell growth } \\
\hline Growth additive & None & $1.25 \%$ glycine (at $\mathrm{OD}_{600} 0.3-0.4$ ) \\
\hline Osmotic stabilizer & None & Hypertonic sucrose (0.4 M; at $\mathrm{OD}_{600}$ 0.3-0.4) \\
\hline $\mathrm{OD}_{600}$ at time of harvest & $\mathrm{OD}_{600} 0.6-0.8$ & $\mathrm{OD}_{600} 0.6-0.8$ \\
\hline \multicolumn{3}{|l|}{ Washing and pulse delivery } \\
\hline Osmotic stabilizer & Isotonic sucrose (0.27 M) & Isotonic sucrose (0.27 M) \\
\hline Cell membrane solubilizer & None & $5 \%(v / v)$ ethanol 5 min prior to pulse \\
\hline DNA amount & $5 \mu \mathrm{g}$ & $0.5 \mu \mathrm{g}$ \\
\hline Pulse parameters & $2.0-2.5 \mathrm{kV} ; 25 \mu \mathrm{F} ; 200-800 \Omega ; 6-9 \mathrm{~ms}$ & $1.8 \mathrm{kV} ; 25 \mu \mathrm{F} ; \infty \Omega ; 12-14 \mathrm{~ms}$ \\
\hline \multicolumn{3}{|l|}{ Outgrowth } \\
\hline Osmotic stabilizer & None & Hypotonic sucrose (0.2 M) \\
\hline Recovery time & $16 \mathrm{~h}$ & $4-6 h$ \\
\hline Transformation efficiency & $2.4 \times 10^{1}$ transformants $\mu g^{-1}$ pMTL 85141 & Up to $7.5 \times 10^{4}$ transformants $\mu \mathrm{g}^{-1}$ pMTL85141 \\
\hline
\end{tabular}


(Figure 3D). This outcome is in agreement with other clostridial electrotransformation protocols that employed phosphate-buffered sucrose as the wash and electroporation buffer, as all such protocols utilize isotonic rather than hypertonic sucrose [25,26,44-46,58,59]. Alternatively, a hypertonic wash and electroporation buffer has been shown to enhance electrotransformation of Streptococcus cremoris and S. lactis [60], Listeria monocytogenes [61], and Lactobacillus sake [62]. Based on these studies and our data presented here it is evident that the degree of osmotic protection required to achieve optimum electrotransformation must be carefully determined for each phase of the electroporation process. While it is commonly assumed that the role of osmotic stabilizer on cell-wall-weakened and electrotransformed cells is strictly protective, it cannot be ruled out that higher electrotransformation efficiencies arise, at least in part, from faster growth rates exhibited by cultures that actively utilize the stabilizer as a carbon and energy source, as observed with the use of sucrose for $C$. pasteurianum (this study) and Lactococcus lactis subsp. cremoris [36].

In addition to the use of cell-wall-weakening additives, the Gram-positive cell wall can be destabilized through the application of high-voltage pulses during electroporation, as stronger electric fields are typically required for Gram-positive compared to Gram-negative bacteria $[23,24]$. Hence, optimization of the electrical parameters must be performed to achieve efficient electroporation without compromising cell viability. We aimed to tailor our electric pulse, defined by the pulse voltage $(\mathrm{kV})$ and corresponding field strength $\left(\mathrm{kV} \mathrm{cm}^{-1}\right)$, capacitance $(\mu \mathrm{F})$, and resistance $(\Omega)$, based on our developed glycine and sucrose regimen. In contrast to most clostridial electroporation procedures, which commonly utilize voltages of 2.0$2.5 \mathrm{kV}$ (5.0-6.25 $\mathrm{kV} \mathrm{cm}^{-1}$ ), optimum electrotransformation of glycine-treated $C$. pasteurianum was found to occur under a lower voltage of $1.8 \mathrm{kV}\left(4.5 \mathrm{kV} \mathrm{cm}^{-1}\right.$; Figure $\left.5 \mathrm{~A}\right)$. Within the clostridia, this low field strength has only been matched by the described protocol for C. acetobutylicum DSM 792 [45]. Increasing the capacitance at voltages of either 1.8 or $2.25 \mathrm{kV}$ generated significantly reduced electrotranformation efficiencies (Figure 5B). In addition, using a higher voltage of $2.25 \mathrm{kV}$ and attempting to truncate the duration of the pulse by using lower resistances of 200 and $600 \Omega$ also produced a reduced number of transformants (Figure $5 \mathrm{C}$ ). Therefore, optimum electrotransformation of glycine-treated C. pasteurianum was found to occur under a relatively low electric field of $4.5 \mathrm{kV} \mathrm{cm}^{-1}$ at $25 \mu \mathrm{F}$ and $\infty \Omega$, generating a time constant of $12-14 \mathrm{~ms}$. We postulate that a relatively weak electric field is best for enhancing electroporation of $C$. pasteurianum as a result of the compromised cell wall associated with the application of our glycine regimen.
A similar effect has been observed using glycine-treated cells of Bacillus cereus, in which glycine had no effect under a high field strength $\left(20 \mathrm{kV} \mathrm{cm}^{-1}\right)$, yet a pronounced positive effect under a low field strength $\left(12 \mathrm{kV} \mathrm{cm}^{-1}\right)$ [56].

To a lesser extent than the Gram-positive cell wall, the cell membrane also acts as a physical barrier to transfer of plasmid DNA into the cell. Aside from the presumed pore formation that occurs immediately following delivery of the electric pulse, little work has been done to enhance electroporation through increasing the extent of membrane permeabilization. Recently, two reports have detailed the use of ethanol as a membrane-solubilizing agent to enhance electroporation of Escherichia coli [41] and Oenococcus oeni [40]. The effect of ethanol, a fermentation end product of $C$. pasteurianum, on growth of species of Clostridium has been extensively studied and it has been shown that ethanol toxicity occurs through direct interaction with the cell membrane resulting in a decreased extent of lipid organization and increased membrane fluidity and cytoplasmic leakage $[42,63]$. It has been proposed that leakage occurs through an ethanol-induced increase in membrane pore size [64], which has clear implications to electroporation. In this report we assessed the electroporation-enhancing effect of ethanol and also extended our approach to butanol. Whereas butanol inhibited electrotransformation and cell growth of $C$. pasteurianum under the conditions tested, we found that ethanol supplemented at an appropriate concentration (5 or $10 \%$ ) had a clear positive effect on electrotransformation (Figure 4). To our knowledge, this study represents the first use of ethanol to enhance electrotransformation within the Clostridium genus.

The investigation of various electrotransformation parameters enabled us to generate a maximum of $7.5 \times$ $10^{4}$ transformants $\mu \mathrm{g}^{-1} \mathrm{DNA}$, a more than 3,000-fold increase compared to our initial attempts using common clostridial electroporation conditions (Table 3). The results reported in this study demonstrate that $C$. pasteurianum ATCC 6013 is amendable to genetic manipulation. Our hope is that our developed gene transfer protocol will allow genetic and metabolic engineering of C. pasteurianum and promote further development of this biotechnologically important microorganism, as the maximum electrotransformation efficiency attained for C. pasteurianum is among the highest reported in the Clostridium genus. However, significant barriers remain to be resolved; namely the low electrotransformation efficiency for plasmids which carry group II intron machinery, such as pSY6catP, necessary for constructing gene knockout mutants in clostridia. Since we have observed a drop in electrotransformation efficiency for pSY6catP (8,498 bp), yet not pHT3 (7,377 bp), a plasmid of comparable size, we suspect the decrease in efficiency is not related to plasmid size. Instead, we speculate that 
C. pasteurianum possesses at least one additional restriction-modification system, in addition to CpaAI, that is specifically active on pSY6catP, but not on pMTL85141. It is likely that additional uncharacterized restriction activities are also responsible for our inability to electrotransform substrates methylated in vitro using CpG and $\mathrm{GpC}$ methyltransferases, despite proper protection against the previously identified CpaAI restriction endonuclease. We are currently conducting genome sequencing of C. pasteurianum which will enable us to identify potential candidate restriction-modification genes that may be responsible for the low electrotransformation efficiency of certain non-pMTL85141 and in-vitro-methylated vectors. Also, it should be mentioned that, even with the reduced electrotransformation efficiency of pSY6catP, our electrotransformation protocol developed herein allows the introduction of group II introns into the $C$. pasteurianum genome in preliminary experiments (data not shown). Thus, should genome sequencing reveal additional restriction-modification genes, our electrotransformation method should enable investigators to knockout such genes using group II introns. Finally, the work here also demonstrates that catP (using thiamphenicol) and ermB (using clarithromycin or erythromycin) comprise effective selection marker systems for performing genetic engineering in $C$. pasteurianum. The pIM13 origin of replication from Bacillus subtilis and the pCB102 and pCD6 origins of replication from $C$. butyricum and $C$. difficile, respectively, were shown to support plasmid maintenance in C. pasteurianum and they round out the vector toolkit now available for genetic engineering in this important bacterium. Taken together, the high-level electrotransformation protocol and the vector and selection tools described herein set the stage for biotechnological exploitation of C. pasteurianum for the first time, thereby opening an important avenue for the production of biofuels from low-value and abundant crude glycerol.

\section{Conclusions}

In this work, M.FnuDII methylation, together with cell-wallweakening, partial membrane solubilization, a low electric field, and osmoprotection enabled the electrotransformation of C. pasteurianum ATCC 6013 at an efficiency of up to $7.5 \times 10^{4}$ transformants $\mathrm{ug}^{-1}$ DNA. The work here also demonstrates the development of a $C$. pasteurianum genetic toolkit currently comprised of two selectable markers (catP-based thiamphenicol selection and ermB-based clarithromycin or erythromycin selection) and three Grampositive origins of replication (pIM13 from Bacillus subtilis, pCD6 from $C$. difficile, and pCB102 from C. butyricum). This is the first report of a genetic transformation procedure for C. pasteurianum and represents a key advancement for this industrially-important bacterium with important implications for low-cost biofuel production.

\section{Methods}

\section{Bacterial strains, plasmids and primers}

The bacterial strains, plasmids, and oligonucleotides utilized in this work are listed in Table 2. E. coli DH5 $\alpha$ was utilized for routine vector construction and propagation, and $E$. coli ER1821 for maintenance of M.FnuDII-methylated E. coli-C. pasteurianum shuttle vectors. C. pasteurianum ATCC ${ }^{\text {тm }}$ 6013 (Winogradsky 5; W5) was acquired from the American Type Culture Collection (Manassas, VA, USA). Modular pMTL-series shuttle vectors [34] were kindly provided by Prof. Nigel Minton (University of Nottingham, Nottingham, UK). Plasmids pFnuDIIM [65], pSC12 [66], and pSY6 [47] were respectively provided by Dr. Geoffrey Wilson (New England Biolabs, Inc. (NEB), Ipswich, MA, USA), Prof. George Bennett (Rice University, Houston, TX, USA), and Prof. Sheng Yang (Shanghai Institutes for Biological Sciences, Shanghai, China). Plasmids pHT3 [49] and pIMP1 [26] were provided by Prof. Terry Papoutsakis (University of Delaware, Newark, DE, USA). Oligonucleotide primers were synthesized and purified by Integrated DNA Technologies (IDT; Iowa City, IA, USA) using standard desalting.

\section{Bacterial growth and maintenance conditions}

Unless stated otherwise, all chemicals were purchased from Sigma-Aldrich (St. Louis, MO, USA) and stock solutions were prepared according to the manufacturer's recommendations. E. coli strains were grown aerobically at $37^{\circ} \mathrm{C}$ in lysogeny broth (LB; $10 \mathrm{~g} / 1 \mathrm{NaCl}, 5 \mathrm{~g} / \mathrm{l}$ Bacto yeast extract, and $10 \mathrm{~g} / \mathrm{l}$ Bacto tryptone). Solid and liquid cultures of recombinant $E$. coli were supplemented with 100,34 , or $30 \mu \mathrm{g} / \mathrm{ml}$ of ampicillin, chloramphenicol, and kanamycin, respectively. For selection of strains harboring two compatible plasmids, antibiotic concentrations were reduced by $50 \%$. Recombinant $E$. coli stocks were stored at $-80^{\circ} \mathrm{C}$ in $15 \%$ glycerol. Unless specified otherwise, growth and manipulation of $C$. pasteurianum was performed in a controlled anaerobic atmosphere $\left(85 \% \mathrm{~N}_{2}\right.$, $10 \% \mathrm{H}_{2}$, and $5 \% \mathrm{CO}_{2}$ ) within an anaerobic chamber (PlasLabs, Inc.; Lansing, MI, USA). Oxygen was purged from growth medium by autoclaving and trace $\mathrm{O}_{2}$ was reduced using a palladium catalyst fixed to the heating unit of the anaerobic chamber. Agar-solidified medium was prepared aerobically and allowed to equilibrate within the anaerobic chamber for at least 36 hours prior to use. Anaerobic conditions were monitored by addition of $1 \mathrm{mg} / \mathrm{l}$ resazurin to both solid and liquid media. Solid and liquid cultures of recombinant $C$. pasteurianum were supplemented with $15 \mu \mathrm{g} / \mathrm{ml}$ thiamphenicol. Cells were maintained as spores on solidified $2 \times$ YTG (16 g/l Bacto tryptone, $10 \mathrm{~g} / \mathrm{l}$ Bacto yeast extract, $5 \mathrm{~g} / \mathrm{l}$ glucose, $5 \mathrm{~g} / \mathrm{l} \mathrm{NaCl}$, and $12 \mathrm{~g} / \mathrm{l}$ agar) plates. Sporulated agar plate stocks were prepared by streaking colonies from an exponential-phase culture $\left(\mathrm{OD}_{600}\right.$ of 0.4-0.6) and cultivating for more than seven 
days under anaerobic conditions, followed by exposure and storage in air at $4^{\circ} \mathrm{C}$ for up to two months [67]. For longterm storage, vegetative stock cultures $\left(\mathrm{OD}_{600}\right.$ of 0.4-0.6) were prepared and stored at $-80^{\circ} \mathrm{C}$ in $10 \%$ glycerol by inoculating a single sporulated plate colony into $10 \mathrm{ml}$ $2 \times$ YTG and heat shocking at $80^{\circ} \mathrm{C}$ for 10 minutes to induce germination.

\section{Preparation of protoplasts and assay of CpaAl activity}

Protoplasts of C. pasteurianum were prepared by suspension of cells from a $100 \mathrm{ml}$ culture $\left(\mathrm{OD}_{600}\right.$ of 0.4-0.6) in $25 \mathrm{ml}$ of protoplast buffer $(25 \mathrm{mM}$ potassium phosphate, $\mathrm{pH}$ 7.0, $6 \mathrm{mM} \mathrm{MgSO}_{4}$, and 15\% lactose) containing $200 \mu \mathrm{g} / \mathrm{ml}$ lysozyme, followed by incubation for 45 minutes anaerobically at $37^{\circ} \mathrm{C}$, as described previously $[19,68]$. For preparation of crude protoplast lysates, $25 \mathrm{ml}$ of protoplasts were collected by centrifugation at $8,500 \times \mathrm{g}$ for 20 minutes and lysed by resuspension in $20 \mathrm{ml}$ of TEMK buffer (4 mM Tris-HCl, pH 8.0, $10 \mathrm{mM}$ EDTA, $6.6 \mathrm{mM}$ 2-mercaptoethanol, and $25 \mathrm{mM} \mathrm{KCl}$ ) [26]. After incubation at $37^{\circ} \mathrm{C}$ for 1 hour, cell debris was cleared by centrifugation at 20,000 $\times \mathrm{g}$ for 15 minutes and supernatants containing protoplast extracts were stored at $-80^{\circ} \mathrm{C}$. CpaAI activity was assayed as previously described [20]. Reaction mixtures contained $1.0 \mu \mathrm{g}$ plasmid DNA and $25 \%$ crude protoplast lysate in a total volume of $20 \mu \mathrm{l}$ of $1 \times$ CpaAI reaction buffer $(6 \mathrm{mM}$ Tris- $\mathrm{HCl}$, $\mathrm{pH}$ 7.4, $6 \mathrm{mM} \mathrm{MgCl}_{2}$, and $6 \mathrm{mM}$ 2-mercaptoethanol). Optimal digestion occurred at $37^{\circ} \mathrm{C}$ for $2-4$ hours.

\section{DNA Isolation and manipulation}

Plasmid DNA was extracted and purified from E. coli DH5 $\alpha$ and ER1821 using an EZ-10 Spin Column Plasmid DNA Miniprep Kit from Bio Basic, Inc. (Markham, ON, Canada). Recombinant DNA manipulations were performed according to standard procedures [69]. Taq DNA polymerase, restriction endonucleases, CpG (M. SssI) and GpC (M.CviPI) methyltransferases, Quick Ligation Kit, and $1 \mathrm{~kb}$ DNA ladder were purchased from NEB (Ipswich, MA, USA). Pfu DNA polymerase and RNase A were purchased from Bio Basic, Inc. (Markham, ON, Canada). All commercial enzymes and kits were used according to the manufacturer's instructions.

Plasmid DNA was extracted and purified from $C$. pasteurianum using a previously described method [49]. Briefly, 3-9 $\mathrm{ml}$ of late-exponential phase cells were collected by centrifugation and washed twice in KET buffer (0.5 M KCl, 0.1 M EDTA, and 0.05 M Tris-HCl, pH 8.0) and once in SET buffer (25\% sucrose, 0.05 M EDTA, and $0.05 \mathrm{M}$ Tris-HCl, $\mathrm{pH}$ 8.0). Cells were then suspended in $200 \mu \mathrm{l}$ of SET buffer containing $5 \mathrm{mg} / \mathrm{ml}$ lysozyme and incubated anaerobically at $37^{\circ} \mathrm{C}$ for 20 minutes. RNase A was added to a final concentration of $100 \mu \mathrm{g} / \mathrm{ml}$ and cell lysis and plasmid purification were carried out using the protocol for Purification of Low-Copy Number Plasmid and an EZ-10 Spin Column Plasmid DNA Miniprep Kit from Bio Basic, Inc. (Markham, ON, Canada) beginning with addition of $400 \mu \mathrm{l}$ of alkaline SDS solution II.

Colony PCR of wild-type and recombinant $C$. pasteurianum was performed by suspending single colonies in $50 \mu \mathrm{l}$ colony lysis buffer $(20 \mathrm{mM}$ Tris- $\mathrm{HCl}$, $\mathrm{pH}$ 8.0, containing $2 \mathrm{mM}$ EDTA and 1\% Triton X-100), heating in a microwave for 2 minutes at maximum power setting, and adding $1 \mu \mathrm{l}$ of the resulting cell suspension to a $9 \mu \mathrm{l}$ PCR containing Standard Taq DNA Polymerase (NEB; Ipswich, MA, USA). An initial denaturation of 5 minutes at $95^{\circ} \mathrm{C}$ was employed to further cell lysis. Colonies screened in this manner by suspension in deionized $\mathrm{H}_{2} \mathrm{O}$ failed to yield appreciable amplification.

\section{Vector construction}

Plasmid pFnuDIIMKn was derived from pFnuDIIM to allow methylation of E. coli-C. pasteurianum shuttle vectors and possesses a kanamycin-resistance determinant, as both pFnuDIIM [65] and the E. coli-C. pasteurianum shuttle vectors used in this study carry the same chloramphenicolresistance marker. First, an FRT-kan-FRT PCR cassette was amplified from plasmid pKD4 [70] using primers KnFRT. BlpI.S and KnFRT.XhoI.AS and inserted into the MCS of BlpI/XhoI-digested pET-20b(+) (Novagen; Madison, WI, USA) to generate pETKnFRT. Next, the FRT-kan-FRT cassette was digested out of pETKnFRT using ScaI and EcoRI and subcloned into the corresponding restriction sites within the catP gene of pFnuDIIM to yield pFnuDIIMKn.

Plasmid pSY6catP was derived from pSY6 [47] by swapping the $\operatorname{ermB}$ marker with the catP determinant from $\mathrm{pSC12}$ [66]. The internal BsrGI recognition site within the coding sequence of catP was mutated by introducing two silent mutations using splicing by overlap extension (SOE) PCR to prevent interference with future group II intron retargeting, which requires use of BsrGI. The catP gene was amplified in two parts from template pSC12 using primer sets catP.BclI.S/pSC12. SOE.AS and pSC12.SOE.S/catP.ClaI.AS with 22 bp of overlap between products. The resulting overlapping PCR products were separated on a $2.0 \%$ agarose gel, pierced three times with a P10 micropipette tip, and used as template in a SOE PCR by cycling for 10 cycles prior to adding primers catP.BclI.S and catP.ClaI.As and cycling for 25 additional cycles. The mutated PCR product was purified using a EZ-10 Spin Column PCR Products Purification Kit (Bio Basic, Markham, ON, Canada), digested with $\mathrm{BclI} / \mathrm{ClaI}$, and inserted into the corresponding sites of pSY6 to generate pSY6catP.

Plasmid pMTL85141ermB was derived from pMTL85141 via insertion of the ermB marker from pIMP1 into 
pMTL85141. The ermB gene and associated promoter was PCR-amplified from template pIMP1 using primers ermB.NdeI.S and ermB.PvuI.AS. The resulting $1,238 \mathrm{bp}$ PCR product was purified using an EZ-10 Spin Column PCR Products Purification Kit (Bio Basic, Markham, ON, Canada), digested with NdeI/PvuI, and inserted into the corresponding sites of pMTL85141 to generate pMTL85141ermB.

\section{Preparation of electrocompetent cells and electrotransformation}

For preparation of electrocompetent cells of $C$. pasteurianum using the high-level protocol, a seed culture was first prepared by inoculating $20 \mathrm{ml}$ of reduced $2 \times$ YTG with $0.2 \mathrm{ml}$ of a thawed glycerol stock. The culture was then $20^{-2}$-diluted and, following overnight growth at $37^{\circ} \mathrm{C}, 1 \mathrm{ml}$ of the seed culture was transferred to a $125 \mathrm{ml}$ Erlenmeyer flask containing $20 \mathrm{ml}$ of reduced $2 \times$ YTG. Cells were grown to early exponential phase $\left(\mathrm{OD}_{600}\right.$ of $\left.0.3-0.4\right)$, at which time filter-sterilized stock solutions of $2 \mathrm{M}$ sucrose and $18.77 \%$ glycine were added to respective concentrations of $0.4 \mathrm{M}$ and $1.25 \%$. Growth was resumed until the culture attained an $\mathrm{OD}_{600}$ of 0.6-0.8 (approximately 2-3 h) and $20 \mathrm{ml}$ culture was transferred to a $50 \mathrm{ml}$ pre-chilled, screw-cap centrifuge tube. At this point, all manipulations were performed at $4^{\circ} \mathrm{C}$ using an ice-bath and pre-chilled reagents. Cells were removed from the anaerobic chamber and collected by centrifugation at $8,500 \times \mathrm{g}$ and $4^{\circ} \mathrm{C}$ for 20 minutes. The resulting cell pellet was returned to the anaerobic chamber and washed once in $5 \mathrm{ml}$ of filtersterilized SMP buffer (270 mM sucrose, $1 \mathrm{mM} \mathrm{MgCl}_{2}$, and $5 \mathrm{mM}$ sodium phosphate, $\mathrm{pH}$ 6.5). Following centrifugation, the final cell pellet was resuspended in $0.6 \mathrm{ml}$ SMP buffer.

For transfer of plasmids to C. pasteurianum, E. coli-C. pasteurianum shuttle vectors were first co-transformed with pFnuDIIMKn into $E$. coli ER1821 to methylate the external cytosine residue within 5'-CGCG-3' tetranucleotide recognition sites of CpaAI. Plasmid mixtures were then isolated and $0.5 \mu \mathrm{g}$, suspended in $20 \mu \mathrm{l}$ of $2 \mathrm{mM}$ Tris $-\mathrm{HCl}$, $\mathrm{pH}$ 8.0, was added to $580 \mu \mathrm{l}$ of $C$. pasteurianum electrocompetent cells. The cell-DNA mixture was transferred to a pre-chilled electroporation cuvette with $0.4 \mathrm{~cm}$ gap (Bio-Rad; Richmond, CA, USA), $30 \mu$ l of cold $96 \%$ ethanol was added, and the suspension was incubated on ice for 5 minutes. A single exponential decay pulse was applied using a Gene Pulser (Bio-Rad, Richmond, CA, USA) set at $1.8 \mathrm{kV}, 25 \mu \mathrm{F}$, and $\infty \Omega$, generating a time constant of 12-14 ms. Immediately following pulse delivery, the cuvette was flooded with $1 \mathrm{ml} 2 \times$ YTG medium containing $0.2 \mathrm{M}$ sucrose and the entire suspension was transferred to $9 \mathrm{ml}$ of the same medium. Recovery cultures were incubated for 4-6 hours prior to plating 50-250 $\mu \mathrm{l}$ aliquots onto $2 \times \mathrm{YTG}$ agar plates containing $15 \mu \mathrm{g} / \mathrm{ml}$ thiamphenicol, $4 \mu \mathrm{g} / \mathrm{ml}$ clarithromycin, or $20 \mu \mathrm{g} / \mathrm{ml}$ erythromycin. Plates were incubated for 2-4 days under secondary containment within 3.4 L Anaerobic Jars each equipped with a $3.5 \mathrm{~L}$ Anaerobic Gas Generating sachet (Oxoid Thermo Fisher; Nepean, ON, Canada).

\section{Abbreviations}

BuOH: butanol; DNA: deoxyribonucleic acid; ET: electrotransformaion; EtOH: ethanol; FRT: flippase recognition target; Gly: glycine; LI.ItrB: mobile group II intron from Lactococcus lactis; MCS: multiple cloning site; NR: nonrecombinant; PCR: polymerase chain reaction; SMP: sucrose-magnesiumphosphate (buffer); SOE PCR: splicing by overlap extension polymerase chain reaction; Suc: sucrose; Thr: threonine; Tm: thiamphenicol.

\section{Competing interests}

DAC is a founder and employee of Centurion Biofuels Corporation, at which MEP has also been employed. Centurion Biofuels Corporation has a financial interest in production of biofuels using clostridial microorganisms.

\section{Authors' contributions}

MEP helped conceive of the study, participated in its design and coordination, carried out the transformations, and drafted the manuscript. MMY participated in the study design and coordination. DAC and CPC helped conceive of the study, participated in its design and coordination, and helped to draft the manuscript. All authors read and approved the final manuscript.

\section{Acknowledgements}

This work was supported in part by the Natural Sciences and Engineering Research Council of Canada (NSERC) and the Canada Research Chairs (CRC) program.

Received: 11 January 2013 Accepted: 4 April 2013

Published: 9 April 2013

\section{References}

1. Lee SY, Park JH, Jang SH, Nielsen LK, Kim J, Jung KS: Fermentative butanol production by clostridia. Biotechnol Bioeng 2008, 101:209-228.

2. Zheng YN, Li LZ, Xian M, Ma YJ, Yang JM, Xu X, He DZ: Problems with the microbial production of butanol. J Ind Microbiol Biotechnol 2009, 36:1127-1138

3. Pfromm PH, Amanor-Boadu V, Nelson R, Vadlani P, Madl R: Bio-butanol vs. bio-ethanol: A technical and economic assessment for corn and switchgrass fermented by yeast or Clostridium acetobutylicum. Biomass Bioenerg 2010, 34:515-524.

4. Qureshi N, Blaschek HP: Economics of butanol fermentation using hyperbutanol producing Clostridium beijerinckii BA101. Food Bioprod Process 2000, 78:139-144.

5. da Silva GP, Mack M, Contiero J: Glycerol: A promising and abundant carbon source for industrial microbiology. Biotechnol Adv 2009, 27:30-39.

6. Johnson DT, Taconi KA: The glycerin glut: Options for the value-added conversion of crude glycerol resulting from biodiesel production. Environ Prog 2007, 26:338-348

7. Yang FX, Hanna MA, Sun RC: Value-added uses for crude glycerol-a byproduct of biodiesel production. Biotechnol Biofuels 2012, 5:1-10.

8. Vanhaandel AC, Catunda PFC: Profitability increase of alcohol distilleries by the rational use of by products. Water Sci Technol 1994, 29:117-124.

9. Vasconcelos I, Girbal L, Soucaille P: Regulation of carbon and electron flow in Clostridium acetobutylicum grown in chemostat culture at neutral $\mathrm{pH}$ on mixtures of glucose and glycerol. J Bacteriol 1994, 176:1443-1450.

10. Heyndrickx M, Devos P, Vancanneyt M, Deley J: The fermentation of glycerol by Clostridium butyricum LMG-1212 T2 and LMG-1213 T1 and C. pasteurianum LMG-3285. App/ Microbiol Biotechnol 1991, 34:637-642.

11. Nakas JP, Schaedle M, Parkinson CM, Coonley CE, Tanenbaum SW: Systemdevelopment for linked-fermentation production of solvents from algal biomass. Appl Environ Microbiol 1983, 46:1017-1023.

12. Biebl H: Fermentation of glycerol by Clostridium pasteurianum - Batch and continuous culture studies. J Ind Microbiol Biotechnol 2001, 27:18-26. 
13. Dabrock B, Bahl H, Gottschalk G: Parameters affecting solvent production by Clostridium pasteurianum. Appl Environ Microbiol 1992, 58:1233-1239.

14. Jensen TO, Kvist T, Mikkelsen MJ, Christensen PV, Westermann P: Fermentation of crude glycerol from biodiesel production by Clostridium pasteurianum. J Ind Microbiol Biotechnol 2012, 39:709-717.

15. Khanna S, Jaiswal S, Goyal A, Moholkar VS: Ultrasound enhanced bioconversion of glycerol by Clostridium pasteurianum: A mechanistic investigation. Chem Eng J 2012, 200:416-425.

16. Moon C, Lee CH, Sang Bl, Um Y: Optimization of medium compositions favoring butanol and 1,3-propanediol production from glycerol by Clostridium pasteurianum. Bioresour Technol 2011, 102:10561-10568.

17. Taconi KA, Venkataramanan KP, Johnson DT: Growth and solvent production by Clostridium pasteurianum ATCC (R) $6013^{\mathrm{TM}}$ utilizing biodiesel-derived crude glycerol as the sole carbon source. Environ Prog Sustain Energy 2009, 28:100-110.

18. Ahn JH, Sang Bl, Urn Y: Butanol production from thin stillage using Clostridium pasteurianum. Bioresour Technol 2011, 102:4934-4937.

19. Clarke DJ, Fuller FM, Morris JG: Proton-translocating adenosinetriphosphatase of the obligately anaerobic bacterium Clostridium pasteurianum.1. ATP phosphohydrolase activity. Eur J Biochem 1979, 98:597-612.

20. Richards DF, Linnett PE, Oultram JD: Restriction endonucleases in Clostridium pasteurianum ATCC 6013 and C. thermohydrosulfuricum DSM568. J Gen Microbio/ 1988, 134:3151-3157.

21. Jensen TO, Kvist T, Mikkelsen MJ, Westermann P: Production of 1,3-PDO and butanol by a mutant strain of Clostridium pasteurianum with increased tolerance towards crude glycerol. AMB Express 2012, 2:44.

22. Malaviya A, Jang YS, Lee SY: Continuous butanol production with reduced byproducts formation from glycerol by a hyper producing mutant of Clostridium pasteurianum. Appl Microbiol Biotechnol 2012, 93:1485-1494.

23. Trevors JT, Chassy BM, Dower WJ, Blaschek HP: Electrotransformation of bacteria by plasmid DNA. In Guide to electroporation and electrofusion. Edited by Chang DC, Chassy BM, Saunders JA, Sowers AE. New York: Academic Press Inc; 1992:265-283.

24. Aune TEV, Aachmann FL: Methodologies to increase the transformation efficiencies and the range of bacteria that can be transformed. Appl Microbiol Biotechnol 2010, 85:1301-1313.

25. Jennert KCB, Tardif C, Young DI, Young M: Gene transfer to Clostridium cellulolyticum ATCC 35319. Microbiology-(UK) 2000, 146:3071-3080.

26. Mermelstein LD, Welker NE, Bennett GN, Papoutsakis ET: Expression of cloned homologous fermentative genes in Clostridium acetobutylicum ATCC 824. Bio/Technology 1992, 10:190-195.

27. Leang C, Ueki T, Nevin KP, Lovley DR: A genetic system for Clostridium ljungdahlii: A chassis for autotrophic production of biocommodities and a model homoacetogen. Appl Environ Microbiol 2013, 79:1102-1109.

28. Scott PT, Rood J: Electroporation-mediated transformation of lysostaphin-treated Clostridium perfringens. Gene 1989, 82:327-333.

29. Zhu Y, Liu XG, Yang ST: Construction and characterization of pta genedeleted mutant of Clostridium tyrobutyricum for enhanced butyric acid fermentation. Biotechnol Bioeng 2005, 90:154-166.

30. Klapatch TR, Demain AL, Lynd LR: Restriction endonuclease activity in Clostridium thermocellum and Clostridium thermosaccharolyticum. Appl Microbiol Biotechnol 1996, 45:127-131.

31. Gonzalez-Pajuelo M, Meynial-Salles I, Mendes F, Andrade JC, Vasconcelos I, Soucaille P: Metabolic engineering of Clostridium acetobutylicum for the industrial production of 1,3-propanediol from glycerol. Metab Eng 2005, 7:329-336.

32. Dong HJ, Zhang YP, Dai ZJ, Li Y: Engineering Clostridium strain to accept unmethylated DNA. PLoS One 2010, 5:e9038.

33. Roberts RJ, Vincze T, Posfai J, Macelis D: REBASE-a database for DNA restriction and modification: enzymes, genes and genomes. Nucleic Acids Res 2010, 38:D234-D236.

34. Heap JT, Pennington OJ, Cartman ST, Minton NP: A modular system for Clostridium shuttle plasmids. J Microbiol Methods 2009, 78:79-85.

35. Tyurin M, Padda R, Huang KX, Wardwell S, Caprette D, Bennett GN: Electrotransformation of Clostridium acetobutylicum ATCC 824 using high-voltage radio frequency modulated square pulses. J App/ Microbiol 2000, 88:220-227.

36. Holo H, Nes IF: High-frequency transformation, by electroporation, of Lactococcus lactis subsp cremoris grown with glycine in osmotically stabilized media. Appl Environ Microbiol 1989, 55:3119-3123.
37. Lee SH, Cheung M, Irani V, Carroll JD, Inamine JM, Howe WR, Maslow JN: Optimization of electroporation conditions for Mycobacterium avium. Tuberculosis 2002, 82:167-174

38. Rodriguez MC, Alegre MT, Mesas JM: Optimization of technical conditions for the transformation of Pediococcus acidilactici P60 by electroporation. Plasmid 2007, 58:44-50.

39. Zhang HH, Li YT, Chen XM, Sheng HM, An LZ: Optimization of electroporation conditions for Arthrobacter with plasmid PART2. J Microbiol Methods 2011, 84:114-120.

40. Assad-Garcia JS, Bonnin-Jusserand M, Garmyn D, Guzzo J, Alexandre H, Grandvalet C: An improved protocol for electroporation of Oenococcus oeni ATCC BAA 1163 using ethanol as immediate membrane fluidizing agent. Lett Appl Microbiol 2008, 47:333-338.

41. Sharma AD, Singh J, Gill PK: Ethanol mediated enhancement in bacterial transformation. Electron J Biotechnol 2007, 10:166-168.

42. Baskaran S, Ahn HJ, Lynd LR: Investigation of the ethanol tolerance of Clostridium thermosaccharolyticum in continuous culture. Biotechnol Prog 1995, 11:276-281.

43. Tomas CA, Beamish J, Papoutsakis ET: Transcriptional analysis of butanol stress and tolerance in Clostridium acetobutylicum. J Bacteriol 2004, 186:2006-2018.

44. Allen SP, Blaschek HP: Electroporation-induced transformation of intact cells of Clostridium perfringens. Appl Environ Microbiol 1988, 54:2322-2324.

45. Nakotte S, Schaffer S, Bohringer M, Durre P: Electroporation of, plasmid isolation from and plasmid conservation in Clostridium acetobutylicum DSM 792. App/ Microbiol Biotechnol 1998, 50:564-567.

46. Zhou YT, Johnson EA: Genetic-transformation of Clostridium botulinum Hall A by electroporation. Biotechnol Lett 1993, 15:121-126.

47. Shao L, Hu S, Yang Y, Gu Y, Chen J, Jiang W, Yang S: Targeted gene disruption by use of a group II intron (targetron) vector in Clostridium acetobutylicum. Cell Res 2007, 17:963-965.

48. Heap JT, Kuehne SA, Ehsaan M, Cartman ST, Cooksley CM, Scott JC, Minton NP: The ClosTron: Mutagenesis in Clostridium refined and streamlined. J Microbiol Methods 2010, 80:49-55.

49. Tummala SB, Welker NE, Papoutsakis ET: Development and characterization of a gene expression reporter system for Clostridium acetobutylicum ATCC 824. Appl Environ Microbiol 1999, 65:3793-3799.

50. Guss AM, Olson DG, Caiazza NC, Lynd LR: Dcm methylation is detrimental to plasmid transformation in Clostridium thermocellum. Biotechnol Biofuels 2012, 5:1-6.

51. Buckley ND, Vadeboncoeur C, LeBlanc DJ, Lee LN, Frenette M: An effective strategy, applicable to Streptococcus salivarius and related bacteria, to enhance or confer electroporation competence. Appl Environ Microbiol 1999, 65:3800-3804.

52. Framson PE, Nittayajarn A, Merry J, Youngman P, Rubens CE: New genetic techniques for group B streptococci: High-efficiency transformation, maintenance of temperature-sensitive pWV01 plasmids, and mutagenesis with Tn917. Appl Environ Microbiol 1997 63:3539-3547.

53. Helmark S, Hansen ME, Jelle B, Sorensen Kl, Jensen PR: Transformation of Leuconostoc carnosum 4010 and evidence for natural competence of the organism. Appl Environ Microbiol 2004, 70:3695-3699.

54. McDonald IR, Riley PW, Sharp RJ, McCarthy AJ: Factors affecting the electroporation of Bacillus subtilis. J Appl Bacteriol 1995, 79:213-218.

55. Peng D, Luo Y, Guo S, Zeng H, Ju S, Yu Z, Sun M: Elaboration of an electroporation protocol for large plasmids and wild-type strains of Bacillus thuringiensis. J App/ Microbiol 2009, 106:1849-1858.

56. Turgeon N, Laflamme C, Ho J, Duchaine C: Elaboration of an electroporation protocol for Bacillus cereus ATCC 14579. J Microbiol Methods 2006, 67:543-548.

57. Hammes W, Schleife K, Kandler O: Mode of action of glycine on biosynthesis of peptidoglycan. J Bacterio/ 1973, 116:1029-1053.

58. Marvaud JC, Eisel U, Binz T, Niemann H, Popoff MR: TetR is a positive regulator of the tetanus toxin gene in Clostridium tetani and is homologous to BotR. Infect Immun 1998, 66:5698-5702.

59. Oultram JD, Loughlin M, Swinfield TJ, Brehm JK, Thompson DE, Minton NP: Introduction of plasmids into whole cells of Clostridium acetobutylicum by electroporation. FEMS Microbiol Lett 1988, 56:83-88.

60. Powell IB, Achen MG, Hillier AJ, Davidson BE: A simple and rapid method for genetic transformation of lactic streptococci by electroporation. Appl Environ Microbiol 1988, 54:655-660 
61. Park SF, Stewart G: High-efficiency transformation of Listeria monocytogenes by electroporation of penicillin-treated cells. Gene 1990, 94:129-132

62. Berthier F, Zagorec M, ChampomierVerges M, Ehrlich SD, MorelDeville F: Efficient transformation of Lactobacillus sake by electroporation. Microbiology-(UK) 1996, 142:1273-1279.

63. Ingram LO: Microbial tolerance to alcohols - Role of the cell membrane. Trends Biotechnol 1986, 4:40-44.

64. Kundu S, Ghose TK, Mukhopadhyay SN: Bioconversion of cellulose into ethanol by Clostridium thermocellum - Product inhibition. Biotechnol Bioeng 1983, 25:1109-1126.

65. Lunnen KD, Barsomian JM, Camp RR, Card CO, Chen SZ, Croft R, Looney MC, Meda MM, Moran LS, Nwankwo DO, et al: Cloning Type-Il restriction and modification genes. Gene 1988, 74:25-32.

66. Zhao YS, Hindorff LA, Chuang A, Monroe-Augustus M, Lyristis M, Harrison ML, Rudolph FB, Bennett GN: Expression of a cloned cyclopropane fatty acid synthase gene reduces solvent formation in Clostridium acetobutylicum ATCC 824. Appl Environ Microbiol 2003, 69:2831-2841.

67. Awang GM, Jones GA, Ingledew WM: The acetone-butanol-ethanol fermentation. CRC Crit Rev Microbiol 1988, 15:S33-S67.

68. Kell DB, Peck MW, Rodger G, Morris JG: On the permeability to weak acids and bases of the cytoplasmic membrane of Clostridium pasteurianum. Biochem Biophys Res Commun 1981, 99:81-88.

69. Sambrook J, Fritsch EF, Maniatis T: Molecular cloning: A laboratory manual. In 2 edition. Cold Spring Harbor Press: Cold Spring Harbor; 1989.

70. Datsenko KA, Wanner BL: One-step inactivation of chromosomal genes in Escherichia coli K-12 using PCR products. Proc Natl Acad Sci U S A 2000, 97:6640-6645.

doi:10.1186/1754-6834-6-50

Cite this article as: Pyne et al.: Development of an electrotransformation protocol for genetic manipulation of Clostridium pasteurianum.

Biotechnology for Biofuels 2013 6:50.

\section{Submit your next manuscript to BioMed Central and take full advantage of:}

- Convenient online submission

- Thorough peer review

- No space constraints or color figure charges

- Immediate publication on acceptance

- Inclusion in PubMed, CAS, Scopus and Google Scholar

- Research which is freely available for redistribution 